\title{
EL «CAMINO PORTUGUÉS» DE SANTIAGO, PAISAJES MÁS PAISANAJE
}

\author{
José Antonio Sotelo Navalpotro, María Sotelo Pérez e Ignacio Sotelo Pérez ${ }^{1}$
}

\section{RESUMEN}

En el presente trabajo descendemos al estudio de la ruta del Camino portugués de Santiago, para analizar un territorio con identidad geográfica propia. Al estudiar el paisaje, en general, y encuadrado en nuestra zona de estudio, encontramos dos grandes temas: uno es el paisaje visual, cuya consideración corresponde a un enfoque más próximo al estético; y, el otro, el que podría denominarse «paisaje total», que identifica al paisaje con el medio. Igualmente señalar que lo que se comprueba en los últimos tiempos es que en esta ruta se está dando un incremento considerable que lo integran, cada vez más, peregrinos -si es que se les puede seguir llamando así- y turistas que conforman un paisanaje que, con el decurso de los siglos, se integran en los paisajes totalmente «antropizados» de un territorio con identidad geográfica propia, y que en España se extiende en un trazado prácticamente recto, entre Tui y Santiago de Compostela. Poco a poco, el turista calificable desde diferentes perspectivas -religioso, termal,..-, va a encontrarse en el espacio que recorre el denominado «Camino Portugués» de Santiago con un paisaje que se presenta como la yuxtaposición de una serie de perfiles esquemáticos integrados por una compleja realidad en la que confluyen aspectos sincrónicos y diacrónicos del medio físico, humano y económico de esta zona costera del sur de Galicia. Espacio rural tradicional, en el que el minifundio va dejando paso a las nuevas necesidades (infraestructuras viarias, tendido eléctrico,...) y a los nuevos espacios «rururbanos». Y es que en Galicia todo es «transición», incluyendo los paisajes, por lo que trataremos de la descripción de lo mismos, haciendo referencia a los «paisajes naturales» y a los «antrópicos», diferenciando entre estos últimos, diversos tipos calificables como rurales, urbanos y «rururbanos», todos ellos con un denominador, la percepción subjetiva del perceptor, ora peregrino ora turista, consumidor de un espacio que para

1. Instituto Universitario de Ciencias Ambientales (IUCA/UCM). Grupo de Investigación de la Universidad Complutense de Madrid: «Desarrollo y Gestión Ambiental del Territorio» (UCM-930539). 
Otero Pedrayo tenía mucho de mágico. Junto a lo anterior destacar que el turismo se está convirtiendo en uno de los sectores fundamentales de la economía de ciudades como Pontevedra, sin embargo, no está exento de problemas, riesgos y dificultades, no sólo en materia de conservación sino también de puesta en valor y, por ende, de gestión del propio patrimonio (ya sea a la hora de conciliar uso residencial con el turístico de la propia ciudad, la dotación de infraestructuras necesarias, proyectos de información y documentación no sólo para turistas sino también para residentes...). Al abordar la problemática entre turismo y el propio patrimonio, las dificultades para compatibilizar conservación y explotación adquieren características específicas.

Palabras clave: paisaje, Paisanaje, espacios naturales, «rururbanización», paisajes urbanos, turismo.

\section{ABSTRACT}

The «Portuguese way» of Santiago, landscapes and civilians

In the present work, we descend to the study of the route of the Portuguese Camino de Santiago, to analyze a territory with its own geographical identity. By studying the landscape in general, and framed in our study area, there are two major issues: One is the visual landscape, the consideration corresponds to a closest to the aesthetic approach; and the other, which could be called «overall landscape» which identifies the landscape with the environment. Also be noted that what is found in recent times is that this path is taking a considerable increase comprising it, increasingly pilgrims - if they can keep calling so- and tourists that make up a landscape that, with the course of the centuries, fully integrated into the «anthropic» landscapes of a territory with its own geographical identity, and that in Spain it extends in a substantially straight path, between Tui and Santiago de Compostela. Little by little, the scoring tourist from different perspectives -religious, thermal,... - will be in the space that runs the so-called «Portuguese Way» of Santiago with a landscape which it is presented as the juxtaposition of a series of schematic profiles consist of a complex reality that blends aspects synchronous and diachronic of physical, human and economic environment of this coastal area of southern Galicia. Traditional rural areas, where small farms giving way to new needs (Road infrastructure, power lines,...) and new spaces «rururban». And in Galicia everything is «transition» including landscapes, so we try to the description of same, referring to the «landscapes» and the «anthropic», differentiating between them, various types qualifying as rural, urban and «rururban», all with a denominator, the subjective perception of the perceiver, pray pilgrim prays tourist, consumer space that Otero Pedrayo had a lot of magic. Along with the above noted that tourism is becoming one of the key sectors of the economy of cities like Pontevedra, however, it is not without its problems, risks and difficulties, not only for conservation but also enhancement and therefore, management of own assets (either in reconciling residential with the tour of the city itself, the provision of infrastructure necessary information and documentation projects not only for tourists but also for residents...). In addressing the problem between tourism and heritage itself, difficulties in reconciling conservation and exploitation acquire specific features.

Keywords: landscape, civilians, natural areas, «rurbanization», urban landscapes, tourism. 


\section{PRIMERA APROXIMACIÓN}

En nuestra Geografía de andar y ver, señalaría el profesor Manuel de Terán, cobran notable importancia los denominados paisajes de origen religioso, hoy perfectamente asumidos por la sociedad de consumo. Entre éstos destacar la notable relevancia adquirida, siglo tras siglo, por el denominado Camino de Santiago, y en los último años, por el sector español del denominado «Camino portugués», cuyos paisajes y paisanajes conforman el tema de estudio de la presente disertación científica, sin prueba explícita, que es como definía Ortega y Gassett el «ensayo», dedicado a uno de los más destacados geógrafos de la España actual, el profesor Alfredo Morales Gil, magnífico profesional, mejor persona y gran amigo.

La peregrinación jacobea desde Portugal, suele leerse en las guías al uso, se intensifica a partir de la independencia de este país a mediados del siglo XII, aunque presumiblemente ya existía en la Alta Edad Media. Desde ese momento el culto jacobeo y la peregrinación a Compostela, considerada como una de las señas de identidad de la cultura europea, tuvieron en tierras lusitanas una proyección muy importante. Aunque nos vamos a detener en los paisajes del trayecto español, no debemos olvidar que durante siglos el pueblo portugués contribuyó a esta experiencia colectiva con altos niveles de participación, siempre apoyado con singular fortuna con el ejemplo de reyes, nobles y altos clérigos (basta con recordar que la mayor parte de la red viaria de Portugal fue testigo, desde el siglo XII hasta nuestros días, del caminar de los peregrinos desde diversos núcleos de población portugueses hasta la meta compostelana). Las motivaciones, tal y como señalamos, para esa peregrinación eran religiosas, si bien, como consecuencia directa de este denso y secular flujo de personas que poblaron los caminos de Santiago, se establecieron entre Portugal y España notable canales de intercambio cultural, económico y de pensamiento (verdaderos fenómenos de transculturación que han dejado su «huella» en el territorio). Y es que el «Camino Portugués» en España (en las tierras gallegas), en su suave discurrir hacia el norte, hace uso de caminos antiguos que cruzan bosques, tierras de labor, aldeas, villas y ciudades históricas, senderos que salvan canales de agua a través de puentes de traza medieval, caminos matizados por la presencia de capillas, iglesias, conventos, petos de ánimas y cruceros, en los que no falta la confortadora imagen de «Santiago Peregrino», acompañando al caminante, hoy transformado en no pocos casos, en turista que consume el espacio recorrido.

Hace ya más de tres décadas, en Anales de Geografía de la Universidad Complutense de Madrid publiqué un artículo titulado: «Paisaje, Semiología y Análisis Geográfico», cuyas páginas relativas a los «paisajes» pueden servirnos ahora como introducción». Y es que en los estudios del medio ambiente, tanto para su planificación como en cuanto a su función soporte de la ordenación 
territorial, el paisaje posee una notable importancia. Su doble función, de mediador vital con el entorno y de reflejo del quehacer histórico del ser humano, le confiere un valor de nexo conceptual entre el hombre y el espacio geográfico, haciéndose siempre que se quiera estudiar, este último, inevitable su consideración. Desde esta perspectiva, puede sernos de utilidad aproximarnos a la «Semiología» o «Semiótica», pues han probado a lo largo de los últimos años su validez en el campo científico de la Lingüística. Sin embargo, no acaba en esta ciencia su posible aplicación; los logros obtenidos durante su adaptación (desde que Ferdinand de Saussure publicara, en 1916, su «Curso de Lingüística General») hace posible el que se intente trabajar con ella en otros dominios científicos (v. gr.: el ámbito del análisis geográfico). De hecho, las próximas líneas tratarán de desarrollar las posibles relaciones existentes entre los significados que, soterradamente, enmarcan los significantes «paisaje» y «Semiología», en su relación con el análisis geográfico del medio, con el fin de interpretar los paisajes del Camino Portugués. Y es que, en primer lugar, destacar el intento de definir lo que se ha dado en denominar «tipos de paisajes», data de épocas y tiempos remotos, como lo atestigua la existencia de nombres de lugares que hacen referencia, a todos los temas. Estas aproximaciones a la diferenciación de los rasgos naturales surgen de las necesidades que tenemos los seres humanos por llegar a comprende y, por qué no, dominar los diferentes espacios vitales o «hábitat».

Por otra parte, en segundo lugar, debemos de ser conscientes que la descripción de un paisaje se presenta al mismo tiempo como una tarea difícil y atractiva, de contornos imprecisos, que es prudente delimitar; es menester, en efecto, tomar algunas decisiones previas acerca de la conveniencia de centrarse en resaltar formas y colores o de dirigirse, en cambio, hacia el estudio de los paisajes. Igualmente, no debemos olvidar que el paisaje, en su concreción ha presentado - desde un punto de vista diacrónico- distintas formas y relaciones. En un principio el paisaje únicamente estaba constituido por los elementos del medio físico, si bien, la aparición del hombre añadió nuevos elementos al mismo. De forma gradual, el paisaje se convirtió en cúmulo de elementos físicos, bióticos y antrópicos. De aquí el que a la hora de acercarnos al paisaje sea «difícil dar una explicación cumplida de las acepciones y origen del término» (González Hernández, 1981). El gran número de términos que se han creado pueden, fácilmente, dar lugar a error por lo que creemos de utilidad aproximarnos a ellas, aunque de forma breve. ${ }^{2}$

2. En las explicaciones del término paisaje, paysage o, sus más o menos equivalentes Landscape, Landschaf,... se hace siempre referencia al arte. El «webster's New World Dictionary» (1954) nos dice que Landscape significa: 1. Imagen que representa una escena natural terrestre, tal como una pradera, bosque, montaña,... 2. Rama de la pintura, fotografía, etc., que se ocupa de tales imágenes. 3. Extensión de escenario natural, percibida por el ojo en una sola visión. Al 
De lo expuesto puede deducirse la polivalencia y equivocidad de la palabra paisaje, y tomarla unas veces como término estético, otras como ecológico o geográfico, según convenga la expresión. Porque la distinción no responde con exactitud, como quizá cabría esperar, al lenguaje común por un lado, y, al científico por otro; existen multitud de descripciones literarias, como tendremos ocasión de comprobar, que podrían figurar en un libro de ecología o de geografía; y hay también estudios científicos del paisaje que lo consideran desde el único prisma de la belleza. Tampoco responde a estos o aquellos tiempos; los clásicos veían el paisaje desde una perspectiva amplia e integradora, superando los aspectos puramente estéticos para dar cabida a la noción de espacio; no tenían, sin embargo, un término unívoco y monosémico para nombrarlo: «Los pueblos más humanistas no tuvieron una palabra para nombrar al paisaje; a esa entidad donde están reunidos todos los campos, los bosques, playas y cielo que lo componen. Unas veces lo llamaban species (figura, vista, aspecto, fisonomía); otras, locus (lugar, país); otras facies (rostro, semblante, aspecto); otras situs (sitio, paisaje)». Esta visión centrada en la vida y el cultivo se conserva y concreta en la palabra que nace en las lenguas romances: paysage, paisaje, paisatge; su origen lo encontramos en el latín pagensis, campestre, el que vive en el campo, a través del francés pays, inicialmente territorio rural; la palabra país aparece en la literatura Castellana en el año 1597; la palabra paisaje en 1708, aunque el término pago -distrito agrícola-, del mismo origen, sea mucho más remoto, 1095, y todavía se conserve - por estos pagos-. Mas, como comprobamos anteriormente, al exponer las distintas definiciones, esta carga etimológica se pierde en las significaciones modernas (Ramos, 1986). ${ }^{3}$

considerar sólo la escena natural, este diccionario excluye el paisaje urbano, y, al confiar la significación al medio terrestre, excluye el marino. Nuestro diccionario de la «Real Academia de la Lengua» considera exclusivamente el aspecto artístico. «Paisaje es: Pintura o dibujo que representa cierta extensión de terreno. Porción de terreno considerado en su aspecto artístico». Sin embargo, numerosas enciclopedias y algunos diccionarios comprenden además de una acepción culta, una científica. Por ejemplo: Paisaje: Porción de superficie terrestre, provista de limites naturales, donde los componentes naturales (rocas, relieve, clima, aguas, suelos, vegetación, mundo animal) forman un conjunto de interrelación e interdependencia. (Pequeña Enciclopedia Soviética, Vol. 5, pág. 350).

3. El contenido del término y de sus derivados -paisajístico,...- no queda comprendido en las mencionadas definiciones de la«Academia». Así, expresiones como paisaje urbano, paisaje industrial opaisaje mral no encajan, efectivamente, de modo pleno en estas definiciones; no obstante, ladiferencia se verá acrecentada considerablemente cuado se sobrepase el marco de la estética para entrar en el área de los recursos geográficos, considerándose al paisaje sujeto de la ordenación territorial. Esta dificultad de concretar el concepto se ilustra aúncuando se considera la diversidad de definiciones que, junto a las anteriormente tratadas, intentan concretarlo: «El paisaje se entiende como la posesión contemplativa y desinteresada del mundo físico circundante» (Lapesa, 1972). «El paisaje es el escenario de la actividad humana» (Laurie, 1970). «El concepto de paisaje engloba una fracción importante de los valores plásticos y emocionales del medio natural» (Sancho, 1980). «Complejo de Interrelaciones derivadas de la interacciónde 
Aparecen, en definitiva, al estudiar el paisaje dos grandes temas: uno es el paisaje visual, cuya consideración corresponde a un enfoque más próximo al estético; el otro es el que podría denominarse «paisaje total», que identifica al paisaje con el medio. Ahora bien, de lo anteriormente expuesto podemos deducir un común sustrato, formado por un espacio, porción de terreno, situs, y una determinada percepción de ese territorio. En otras palabras, hay una realidad espacial que se percibe bajo un cierto prisma, una fuente de información más o menos directamente asimilable que se recoge también en mayor o menor medida. Pero a estos dos sumandos - configuradores del paisaje- habría que añadir un tercero, que ha quedado implícito: el sujeto de la percepción, el hombre. Y este es el quid de la cuestión, pues, ¿existe una realidad objetiva del paisaje unida a la realidad geográfica del territorio -incluso identificada con ella-, o hay tantos paisajes como percepciones o aún perceptores? (Ramos, 1986). También se ha querido ver en el paisaje lo aparente, aproximándose al hecho de que la realidad geográfica es una, si bien los paisajes son varios, tantos como distancias, luces o ángulos en perspectiva. En realidad, el paisaje surge de la mirada de los seres humanos, de tal forma que podemos afirmar que cada paisaje es recreado, es decir, vuelve a nacer en el momento en que lo observan espectadores diferentes. Esa apariencia existe sólo en la siqué del observador, de manera que el análisis del paisaje se dirigirá más a las personas que lo perciben, que al territorio. Así, pues, el paisaje queda sujeto a la doble indeterminación que su apariencia cambiante le añade y a la capacidad e interés del que lo contempla. El paisaje percibido es el resultado de la interacción existente entre el observador y el entorno: éste «sugiere» distinciones y relaciones, aquel escoge, organiza y cambia de sentido lo que ve; cada individuo crea y lleva dentro de sí su propia imagen. Pero está claro que existen además imágenes colectivas, propias de grupos humanos que concuerdan en su apreciación, y paisajes en abstracto que han cobrado universal significado, como el bosque («Arborum altitudo nos delectat»). Otros, por el contrario, opinan que el paisaje es el territorio en clave histórica, una manifestación sintética de las condiciones y circunstancias geológicas y fisiográficas que concurren en un «pats», un agregado de todos los rasgos que, en interacción, aparecen en un territorio, un «pattern» de ecosistemas. ${ }^{4}$

rocas, agua, aire, plantas, animales y hombres» (Sancho, 1980). «El paisaje, en su totalidad, es la agregación de todos los factores interrelacionados, que ocupan la superficie total de la tierra» (Corominas, 1973). «El paisaje se dibuja como conjunto procedente de la agregación de los caracteres físicos del medio físico, y de los rasgos físicos del medio biótico» (Aguilo, 1981). «Un medio natural, frecuentemente condicionado por las actividades socio-económicas, aparece como paisaje a los ojos del hombre, transformado por los factores socio-culturales» (Corominas, 1973).

4. Los enfoques que ponen el énfasis en la perceción y las que lo sitúan en el territorio se concilian en otro elemento integrador; el paisaje como fenosistema, parte fácilmente aceptable y perceptiblede un sistema de relaciones subyacentes; criptosistema de observación menos directa; el 
En algunos casos la acción que se ejerce sobre la naturaleza es apresurada, demoledora, en lucha abierta con ella, degradante: lo que sustituyó a esta percepción moral o ética del paisaje fue la visión del ingeniero. Estamos sólo empezando a estudiar los orígenes y crecimiento del paisaje del ingeniero, y la insidiosa manera en que su filosofía ha afectado nuestras actitudes hacia todo el paisaje. A La acción del hombre y de la mujer sobre el paisaje corresponde otra en sentido opuesto, acaso menos patente pero igualmente real. Pese a que los artistas plásticos y los escritores lo hayan descubierto en un determinado momento y lo interpreten de manera diferente en cada nuevo período histórico o cultural, el paisaje no es la simple escenografía que nos rodea, sino el molde físico al que sumando el humano llegan a conformar el cuadro geográfico que de alguna manera determina las costumbres de una zona, región o comarca, forma el carácter y explica las cualidades y los gustos de la gente (paisanaje) que lo vive. De aquí que el paisaje se relacione íntimamente con la manera de ser de quien lo habita y lo puebla, ayudándole a su comprensión y a su más exacto conocimiento.

Al hilo de lo señalado podemos diferenciar tres cuestiones: en primer lugar, la relación «significante-significado», o lo que en nuestro caso es lo mismo, «efecto-causa», es total. Por ello, podemos hablar de signos característicos de un aspecto geográfico. No obstante, en razón de los denominados fenómenos de convergencia, divergencia y remanencia (remontándonos a elementos espaciotemporales lejanos al propio observador), los códigos pueden llegar a ser indescifrables, ya que la dualidad significante-significado pueden ser de naturaleza muy diferente. La posibilidad de hallar los significados propios de los distintos significantes es aquí consecuencia última del nivel alcanzado por el conocimiento de la «ciencia», en general, y por lo que a la Geografía se refiere, de los avances de esta última en particular.

En segundo lugar, nos encontramos con la noción de perturbación. Puede servirnos como ejemplo el hecho de que en la actualidad, en unas ciudades que no cesan de crecer, el individuo no puede retener más que los signos más activos

paisaje es el dominio de la percepción sensible, de la intuición. Y como se ha señalado, penetrante, siendo obligado en el estudio de los paisajes, el reconocimiento de una tensión que lo singulariza, en buena medida; diferenciando entre los aspectos científicos y estéticos, entre lo racional y lo sensible (Ramos, 1986). Pero volvamos a la interacción observador-territorio, para comprobar que tal relación no se limita a configurar la percepción, sino que tiene consecuencias de mayor alcance. Ahora bien, el vocablo paisaje puede verse calificado por algunos elementos tales como: natural, rural, agrario; o bien, con otros como urbano, industrial, etc. Así, para algunos «el paisaje era bello en tanto que reflejase la perfección moral o ética a la que aspiran supuestamente todos sus habitantes. La perfección o plenitud no residía en el paisaje mismo, sino en el espíritu que lo había alumbrado y lo continuaba animando». En otras ocasiones la grandiosidad de la acción humana se yergue, apagándola, sobre la naturaleza, como en el Escorial, donde «Herrera se bebió todo el paisaje». (Jackson, 1976), (Río Sainz). 
de los existentes en el sistema urbano (ahora bien, debemos tener en cuenta -a la hora de estudiar los efectos derivados de la acción geográfica de esos signos-que los grupos de los mismos, ante los que se puede encontrar cualquier observador, son, por lo general, mucho más perturbadores que los signos aislados, precisamente porque los elementos de los sistemas a los que pertenecen no van a aparecer aislados).

En tercer, y último lugar, encontramos el concepto de campo. A la hora de realizar cualquier estudio de «Semiología» en relación con la Geografía, cobra relativa importancia el enmarcar el tratamiento de los diferentes signos (con sus respectivos significantes y, por ende, significados), en el campo científico con el que estamos trabajando. De hecho, la óptica con la que trabajaremos los diferentes signos geográficos, fruto de nuestro estudio, dependerá del análisis científico que les vayamos a dar. Si estamos trabajando con los paisajes del "Camino Portugués» de Santiago, el paisaje variará según le demos un enfoque geomorfológico, biogeográfico, urbano,..., o de paisaje en su totalidad (si es que se puede hablar del estudio del paisaje, globalmente, trabajado). Ahora bien, llegados a este punto nos preguntaremos: ¿podemos hablar de análisis de los paisajes o por el contrario, hemos de remitirnos a unos signos inherentes a los paisajes? El paisaje, tal y como se ha ido poniendo de manifiesto, se forma mediante la interrelación de elementos naturales y humanos. Sin embargo, el paisaje, en lo que a sus aspectos más específicos se refiere, aparece como indicador, más o menos revelador, de una combinación de otro dependerán de la naturaleza de los casos de los paisajes geográficos (Fremont, 1974). «Grosso modo», sus principales componentes serían: el relieve, el clima, la vegetación natural, los componentes rurales (agricultura...) y los urbanos. A partir de todos ellos, podremos llegar a estudiar el paisaje como conjunto de signos. No obstante, percibir el paisaje como interrelación de unos signos, puede plantearnos algunos problemas; tales como: el hecho de que un paisaje determinado se nos pueda presentar como el reflejo incompleto y deformado de un conjunto de signos, etc,...; todo esto marcado por el hecho de que las superestructuras socioeconómicas,..., no se nos muestran a la par que los significantes, ora porque aparecen deformados a causa de aspectos de remanencia (supervivencia en un paisaje de sistemas dispares), de convergencia (un mismo significante puede corresponderse con significados diferentes; así, una misma forma geográfica ha podido ser el resultado de distintos mecanismos) y de divergencia (a un único significado pueden corresponder significantes distintos, o la superposición de diferentes campos; v. gr.: en nuestra zona de estudio el éxodo rural, la emigración, puede dar pie, en algunos casos, al mejoramiento de los cultivos de la tierra, a la disminución de la presión demográfica y, a la par, el envejecimiento de la población). Pese a todo, ¿son realmente los elementos del paisaje unos signos, o por el contrario, según las distinciones realizadas por algunos semiólogos, unos índices? Un signo puede 
darnos una información, como en el caso de los elementos que componen un mapa (Semiología gráfica); no obstante, este no es el caso -al menos de forma plena-de los elementos del paisaje, los cuales no pueden ser elegidos a voluntad del investigador. ${ }^{5}$ De una u otra forma, el turista peregrino va a encontrarse ante unos paisajes que va a percibir de forma completa, plena, en los que sincronía y diacronía van a sintetizarse a lo largo de su recorrido, aproximémonos a los mismos.

\section{PAISAJES MÁS PAISANAJeS}

El 16 de agosto en la prensa local compostelana se podía leer: «La Xunta de Galicia por medio de Turismo de Galicia va a conceder subvenciones a diez ayuntamientos de las comarcas de Santiago para el fomento de la accesibilidad de los recursos turísticos en el medio rural. El objetivo de las ayudas, cofinanciadas con el Fondo Europeo Agrícola de Desarrollo Rural (FEADER), es dotar a los municipios de infraestructuras y de señalización adecuadas para facilitar el acceso a los recursos turísticos. La inversión total para estas comarcas es de 182.214 euros.

En lo que respecta al Camino de Santiago, las ayudas recaerán en la parroquia de Furelos, del municipio de Melide, donde se ha aprobado una partida de 45.340 euros para la pavimentación del puente medieval que sirve de acceso al Camino de Santiago a la parroquia de Furelos, de la mencionada cantidad, la Xunta aportará 30.604 euros y el resto cae a cuenta del Ayuntamiento u otros patrocinadores». Semejantes noticias nos ponen en la línea de interpretar, claramente, el denominado Camino Jacobeo, más como una hipotética figura de «Desarrollo Endógeno» (desde la idea según la cual el aspecto económico es importante, pero no lo es más que el desarrollo integral del colectivo y del individuo, en el ámbito moral, cultural, social, político, y tecnológico. Esto permite convertir los recursos naturales en productos que se puedan consumir, distribuir en general), que como un fervor religioso que en la actualidad, como mucho, habría dado paso a un Turismo calificable de religioso.

De hecho, cuando algunos peregrinos prefieren huir de las aglomeraciones y masificaciones del denominado Camino Francés -para muchos el periplo Jacobeo «per se»-, buscan otras alternativas, apareciendo el denominado «Camino Portugués». Sirviéndonos como fuente la web de la «Oficina de acogida al Peregrino», entre enero y julio del 2015, recogieron la Compostela, al

5. De esta forma, planteémonos hasta qué punto puede el «geógrafo inspirarse, para la realización de sus estudios, en el vocabulario y en los métodos utilizados por la «Semiología lingüística». Sin duda ésta es una pregunta tan compleja de responder como indirecto es su planteamiento; pese a todo varios son los intentos que se han realizado, intentos que buscaban una respuesta coherente. 
haber recorrido esta última ruta, un total de 22.967 personas (4.000 más que en el mismo período del año pasado, y 5.000 más que en el último Año Jacobeo, el 2010).

Lo que se comprueba en los últimos tiempos es que en esta ruta se está dando un incremento notable que lo integran, cada vez más, peregrinos -si es que se les puede seguir llamando así- y turistas que conforman un paisanaje que, con el decurso de los siglos, se integran en los paisajes totalmente «antropizados» de un territorio con identidad geográfica propia, y que en España se extiende en un trazado prácticamente recto, entre Tui, ciudad sede episcopal, capital que fue de una de las siete provincias gallegas, de la que el creador del Rexurdimento gallego, Manuel Murguía, escribiera: «iAdiós, pues, campos y ciudad e iglesia; adiós, orillas fecundas y huertos en que florece el naranjo! Sea para vosotros el cielo tan propicio como lo sois para los mortales. Merecíais ser la nueva patria de Diomedes, y que Homero pusiese en labios del héroe, la salutación de Ulises a la isla de los reacios, diciendo: escúchame, oh río, cualquiera que sea tu nombrei, con qué ansias me acerco a ti, libre de las olas y a salvo de las amenazas de Poseidón», y, Santiago de Compostela, cuyo espíritu cultural se recoge en el dístico grabado en la tumba del arzobispo don Bernardo, a saber: «Traxit ab hac vita Bernardus metropolita//post hoc vile solum scandere posse plum.» Otorga una visión de cadencia medieval de la mano de Sicut soles de los Salmos, haciendo olvidar al turista, peregrino o no, el Pallida mors horaciano, en una ciudad actual capital de la Comunidad Autónoma de Galicia, ubicada en la provincia de La Coruña, y, cuyo Casco histórico es Patrimonio de la Humanidad, declarado por la Unesco, en 1985; sede del Gobierno autonómico y del Parlamento, y en la que según la tradición se dio sepultura al Aposto Santiago el Mayor, y de cuya Catedral escribiera Rosalía de Castro, refiriéndose al Santiago caballero: «Del Zebedeo la celeste imagen//como el alma del mártir blanca y bella// y vencedora en su caballo airoso,//que galopando en triunfo el aire rasga.»

Por el caminos, en su recorrido, tal y como se recoge en la información de las guías jacobeas, desde Tui todos siguen la misma ruta. Se atraviesa O Porriño entre las colosales canteras de granito y las húmedas Gándaras de Budiño. Redondela (famosa por su «fiesta do Corpus»), dedica a Santiago su iglesia parroquial, lo mismo que Arcade, a la sombra del castillo de Soutomaior, perfectamente restaurado. Pontevedra cuyo templo más emblemático se encuentra bajo la advocación de la Virgen Peregrina; de original planta en forma de concha de vieira, porque según la tradición encaminaba a los peregrinos descarriados hacia Compostela. De Pontevedra a Caldas de Reis es un tramo tranquilo y sugerente. Desde el atrio de la iglesia barroca de Perdecanai se domina el valle, donde se pierde el románico de Agudelo, los pazos de Curuxal y Casal Novo, y resuenan roncas en el alto campanario de Arcos da Condesa las campanas que 
se funden en la «casa dos campaneiros» de Badoucos. De la mansión romana a la villa gótica, Caldas de Reis -el «Rex» pudo ser Alfonso VII- ofrece restos importantes, el balneario y uno de los mejores robledales urbanos a orillas del Umia. Luego contemplamos los ábsides románicos de Santa María de Vemil y la portada de este mismo estilo en Xanza. Poco después entramos en Pontecesures, donde desemboca el Ulla, ofreciendo lo más exquisito de la gastronomía fluvial: reo, lamprea, trucha, salmón. El río se atraviesa por un largo puente medieval, sobre fundamentos romanos, en el que hizo reformas el Maestro Mateo. Enseguida Padrón nos mete de lleno en la ruta jacobea (ver mapas.$^{\circ} 1 \mathrm{y} \mathrm{n}^{\circ}{ }^{\circ}$ ).

Poco a poco, el turista calificable desde diferentes perspectivas -religioso, termal,...-, va a encontrarse en el espacio que recorre el denominado «Camino Portugués» de Santiago con un paisaje que se presenta como la yuxtaposición de una serie de perfiles esquemáticos integrados por una compleja realidad en la que confluyen aspectos sincrónicos y diacrónicos del medio físico, humano y económico de esta zona costera del sur de Galicia. Así, sobre un oculto basamento geológico, sobre laderas de fuerte pendiente se han ubicado un sinfín de casas diseminadas, fruto de la adaptación de sus habitantes a un medio en

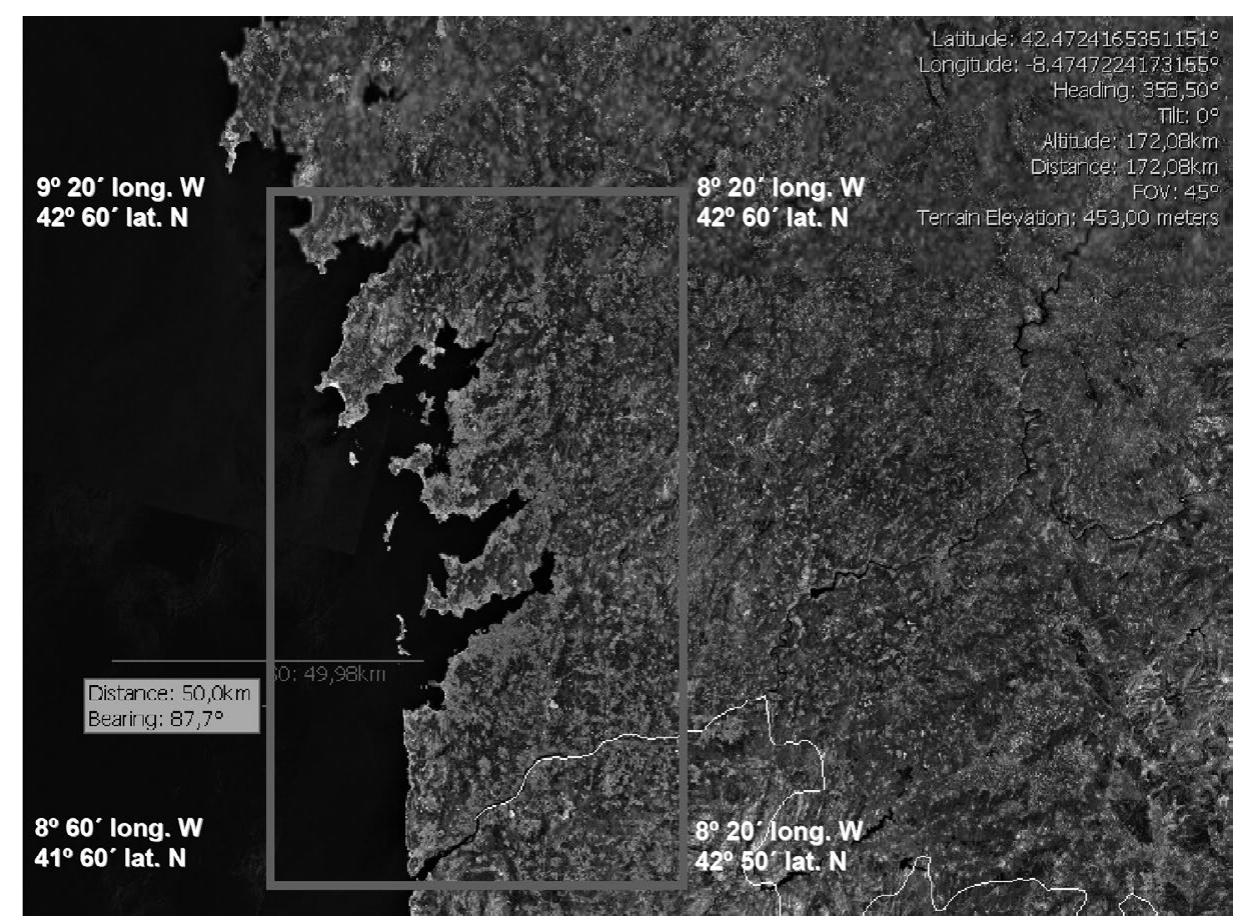

Mapa n. ${ }^{0} 1$. Área de estudio. Fuente: I.G.N. 


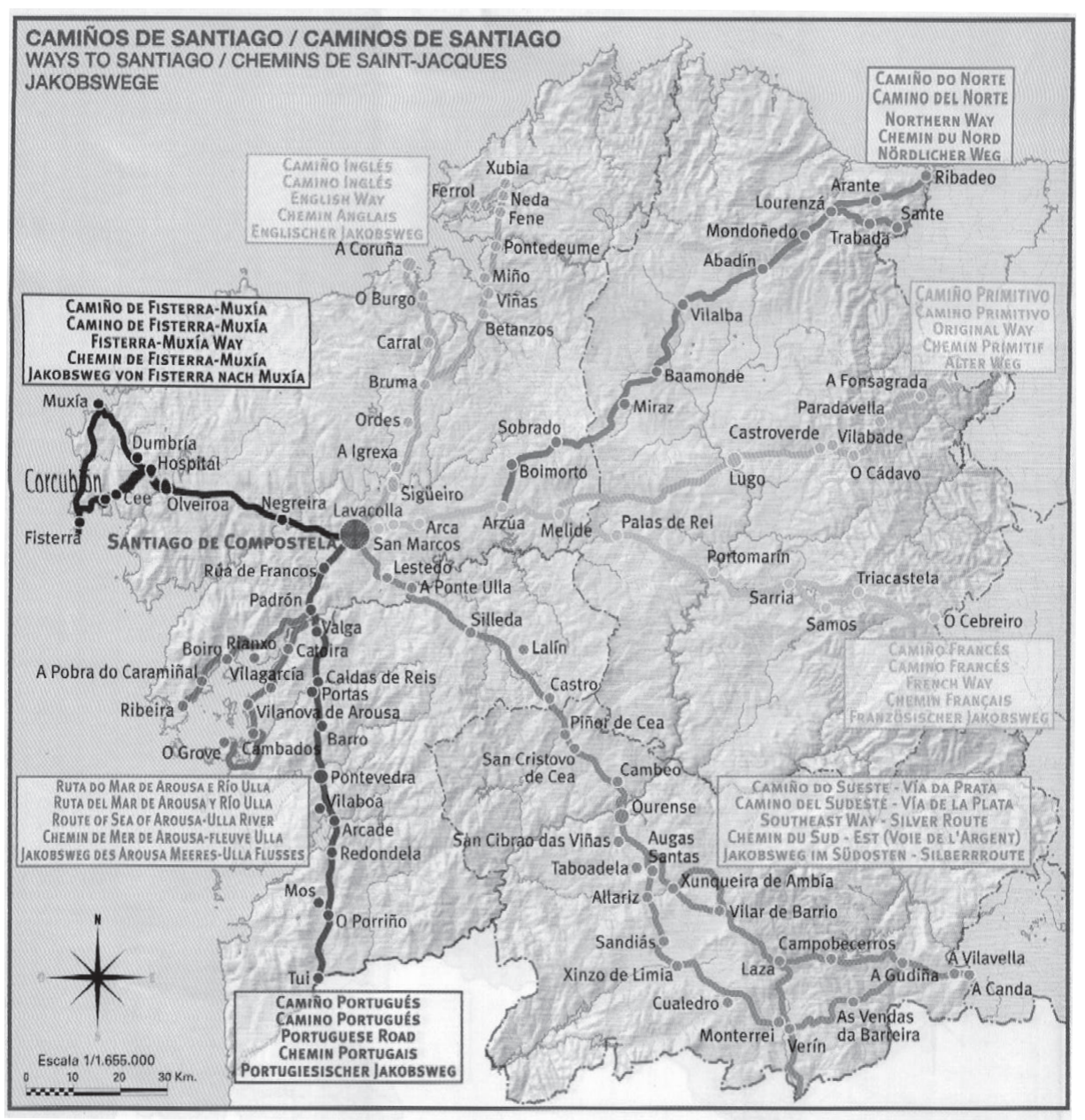

Mapa.$^{\circ}$ 2. Información turística de los distintos «Caminos» de llegada a Santiago.

Fuente: www.Turgalicia.es

ocasiones hostil. Eucaliptos, rebollos, frutales, penetran un espacio marcado por parcelas de pequeñas dimensiones, ayer ocupadas por el maíz o los viñedos, hoy por construcciones fruto de la última especulación del mercado inmobiliario. Espacio rural tradicional, en el que el minifundio va dejando paso a las nuevas necesidades (infraestructuras viarias, tendido eléctrico,...) y a los nuevos espacios «rururbanos». Y es que en Galicia todo, incluyendo los paisajes, es «transición», por lo que trataremos de la descripción de lo mismos, haciendo referencia a los «paisajes naturales» y a los «antrópicos», diferenciando entre estos últimos, diversos tipos calificables como rurales, urbanos y «rururbanos», 
Figura n. ${ }^{\circ}$ 1: Evolución del Modelo de Desarrollo Económico Litoral de Galicia. Rías Altas y Rías Bajas (I)

\begin{tabular}{|c|c|c|c|c|}
\hline \multicolumn{5}{|c|}{ GEOSISTEMA NATURAL } \\
\hline $\begin{array}{l}\text { Relieve y } \\
\text { Geología }\end{array}$ & $\begin{array}{l}\text { Vegetación y } \\
\text { suelos }\end{array}$ & Clima & $\begin{array}{c}\text { Hidrografía y } \\
\text { costa }\end{array}$ & Paisaje \\
\hline $\begin{array}{c}\text { Acantilados } \\
\text { Escarpes Playas } \\
\text { Cerros y tierras } \\
\text { llanos Costa } \\
\text { sinuosa } \\
\text { Rías } \\
\text { Granitos (dos } \\
\text { micas; } \\
\text { Granodioríticos) } \\
\text { Sierras litorales } \\
\text { Río Miño } \\
\text { (desembocadura) }\end{array}$ & $\begin{array}{c}\text { Frondosas } \\
\text { Robles, Castaños, } \\
\text { Hayas, abedules, } \\
\text { Repoblación: } \\
\text { Eucaliptos y pinos } \\
\text { de } \\
\text { Matorral, Pastos } \\
\text { bosque de ribera, } \\
\text { (sustituido por } \\
\text { viñedos) } \\
\text { Leptosoles, } \\
\text { Regosoles, } \\
\text { Cambisoles }\end{array}$ & $\begin{array}{c}\text { Atlántico } \\
\text { húmedo Elevadas } \\
\text { precipitaciones } \\
\text { Vientos costeros } \\
\text { Temperaturas } \\
\text { suaves Elevada } \\
\text { humedad } \\
\text { Soleado al Sur } \\
\text { (verano) }\end{array}$ & $\begin{array}{c}\text { numerosos y } \\
\text { caudalosos Rías } \\
\text { encajadas } \\
\text { (origen tectónico) } \\
\text { Desembocadura } \\
\text { del Miño } \\
\text { Riquísimos } \\
\text { ecosistemas } \\
\text { (aguas tranquilas: } \\
\text { frías, cálidas; } \\
\text { dulces, saladas) } \\
\text { Riquísimas en } \\
\text { nutrientes }\end{array}$ & $\begin{array}{c}\text { Paisaje } \\
\text { homogéneo } \\
\text { Presencia de } \\
\text { numerosas ZEPA } \\
\text { y LIC de la } \\
\text { Red Natura 2000 } \\
\text { Humedales } \\
\text { Artístico } \\
\text { Miradores } \\
\text { Camino de } \\
\text { Santiago Parque } \\
\text { Nacional de las } \\
\text { Islas Atlánticas }\end{array}$ \\
\hline
\end{tabular}

Fuente: Elaboración propia

todos ellos con un denominador, la percepción subjetiva del perceptor, ora peregrino ora turista, consumidor de un espacio que para Otero Pedrayo tenía mucho de mágico.

Entre los «paisajes naturales» más destacables recorridos por el Camino portugués nos encontramos con las Rías. Nuestro ámbito de actuación lo ubicamos en las Rías Bajas gallegas.

Si nos aproximamos a su estudio el término «ría» es un antiguo nombre usado en Galicia, región de recortada costa, para denominar a los profundos entrantes que tan bien desarrollados están, sobre todo, en su parte atlántica. Desde la introducción del término en la literatura científica por Von Richthofen en 1886, sólo se ha adquirido un relativo, e incluso limitado, conocimiento sobre rías. El proceso de consolidación de los paisajes que podríamos calificar de naturales (si es que como tal existen en nuestra zona de estudio), podemos observarlo en el cuadro siguiente, que trata de la evolución del que podríamos denominar «modelo de desarrollo económico» de Galicia (figura n. ${ }^{\circ}{ }^{1}$ ).

Fue en la década de los ochenta, del pasado siglo, cuando «ría» y «estuario», hasta entonces considerados una misma cosa, quedan clasificados por Fairbndge como tipos distintos de estuarios atendiendo a las características fisiográficas de ambos. Desde una perspectiva geológica, las posteriores clasificaciones han ido evolucionando según distintos criterios genéticos, geomorfológicos, etc. Así se llega a distinguir entre estuarios desarrollados en llanuras costeras, y los denominados como rías, en función del relieve costero que presenten; si 
los primeros ocupan costas con relieve bajo, el segundo caso corresponde a antiguos valles fluviales, inundados por el mar, que se han desarrollado en costas con alto relieve. La progresiva adición de parámetros procedentes de otras perspectivas de la ciencia, ya sea física, química o biológica, logró una mayor definición de las características específicas que concurren en los estuarios. Es a partir de aquí cuando se alcanza una mejor comprensión de los mecanismos que influyen en los procesos de sedimentación en el transito de las condiciones fluviales a las marinas de los diferentes medios costeros. En este contexto, la complejidad de los procesos que se dan en este tipo de medios, exigió tener más en cuenta unos parámetros que otros para cada caso de estudio considerado. Así por ejemplo, cuando Dalrymple y colaboradores en 1992 establecen una correlación espacial y temporal entre la energía relativa de las mareas, del oleaje, y de las descargas fluviales, la combinación de estos parámetros va dirigida al establecimiento de un modelo de facies de estuario que sirva de base conceptual para la interpretación del registro geológico en estuarios. El enfoque de la estratigrafia secuencial, iniciado al mismo tiempo en que se despertaba el interés por el proceso del calentamiento global, con la consiguiente elevación del nivel del mar y su repercusión sobre una parte significativa de la población mundial, aumentó la necesidad por conocer la historia transgresiva de los actuales estuarios producidos en valles sumergidos. En consecuencia, se genera un elevado y bien documentado número de trabajos geológicos realizados en muchos estuarios del mundo. Por el contrario, los escasos estudios geológicos realizados en rías continúan considerándose como si se tratara de estuarios, y en general sólo se habla de rías cuando la toponimia así lo exige. No obstante, y a falta de trabajos realizados en otras costas de rías que permitan corroborar los datos obtenidos para las Rías Bajas de Galicia, ya se pueden proponer unas características morfológicas y de distribución de facies sedimentarias claramente diferentes a las establecidas para los estuarios. El 80\% del total del área de las rías, está sometida al dominio de procesos marinos marcadamente definidos por la acción de las olas y de las mareas a los que también se incorporan los fenómenos estacionales de upwelling, procesos que contrastan con los procesos de estuario que sólo se establecen en su parte más interna. El dominio de unos procesos frente a otros, marcan dos zonas de sedimentación muy específica con límites bien diferenciados. En la primera zona, con predominio de procesos marinos, se muestra una heterogénea distribución de sedimentos terrígenos y biogénicos en el sentido transversal, mientras que a lo largo del eje principal y aumentando progresivamente hacia el interior se distribuyen depósitos cohesivos ricos en materia orgánica. En la segunda zona, de interacción fluvio/marina, el río entra en el área, frecuentemente bordeado por llanuras intermareales fangosas, para dar lugar a un sistema canalizado en el que se organizan variadas formas 
arenosas de lecho equivalentes a las que se presentan en los estuarios influidos por la marea (ver Mapa n. ${ }^{\circ} 3$ ).

Casi podría decirse que no se conoce nada sobre rías, pero aún así, surge la pregunta de si el término «ría» podría ser empleado como término sedimentológico en el caso de existir algún carácter distintivo que claramente permita ser usado como criterio de reconocimiento de secuencias sedimentarias en el registro fósil (ver figura . $^{\circ} 2$ ). Desde otro punto de vista, de la investigación realizada en rías se pueden deducir otros campos de investigación aplicada en temas relacionados con el impacto humano en el medio ambiente y también

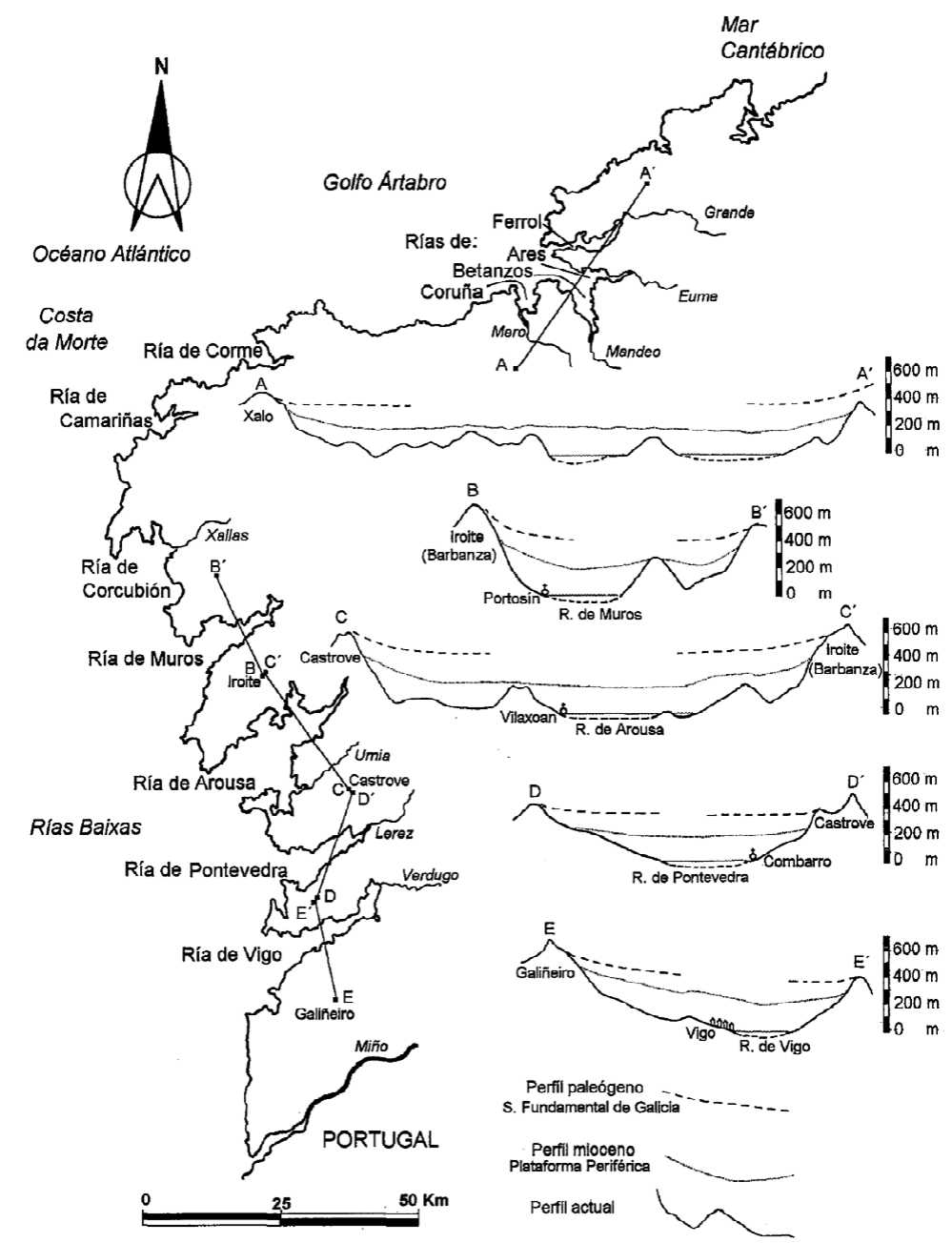

Mapa n. ${ }^{\circ}$ 3. Evolución cenozoica de los perfiles transversales de las rías.

Fuente: Pagés Valcarlos, J.L. (2000) 


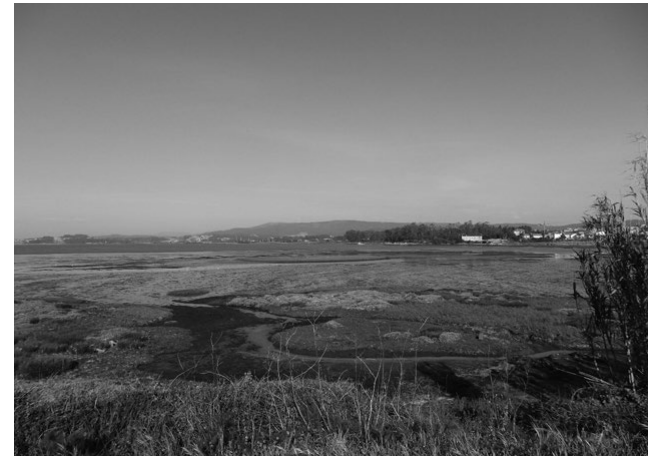

Figura n. ${ }^{\circ}$ 2: Ría de Arousa.

Fuente: María Sotelo Pérez

con el cambio climático global. En primer lugar, el hecho de que las rías constituyan eficaces cuencatrampa de sedimentos las hace igualmente susceptibles a la retención de sustancias contaminantes de procedencia industrial y/o urbana a partir de su asociación con las partículas finas que se encuentran en suspensión en la columna de agua, particularmente en áreas en la que la presencia de upwelling genera una alta tasa de concentración de materia orgánica.

En segundo lugar, las secuencias generadas durante el relleno sedimentario de las cuencas de las rías, contienen evidencias de las variaciones relativas del nivel del mar y también de los cambios climáticos habidos desde el último máximo glacial. En tercer lugar, el enorme impacto que catástrofes ambientales como la del petrolero Prestige pueden tener en espacios relativamente cerrados.

El profesor Torre Enciso publicó en 1958 su síntesis sobre las rías gallegas, en la que junto a la revisión pormenorizada de los estudios anteriores plasma su interpretación del origen de las mismas. Acepta de partida el «alzamiento epirogénico relativamente reciente» observable a través de los perfiles longitudinales de los ríos, en los que habría dejado «un fuerte codo por el que descienden las aguas formando rápidos o cascadas», así como en el fuerte encajamiento de los cursos actuales sobre «un paisaje perteneciente a un ciclo de erosión más antiguo». Enumera los ríos que cumplen estos requisitos y destaca un hecho: el frecuente encajamiento de los cursos fluviales «especialmente en la parte menos distante de su desembocadura, que fue la que sufrió los efectos de la última onda erosiva remontante». La erosión remontante sobre un valle relativamente joven supondría un encajamiento en el sustrato hercínico, dejando colgados fondos de valles antiguos (por ejemplo en el tramo final del Tambre), mientras que por el contrario, la erosión remontante sobre los rellenos aluviales del tramo inferior del Miño, daría lugar a la formación de terrazas fluviales. Destaca asimismo los grandes cambios de régimen fluvial «que experimentaron los ríos durante las alteraciones climáticas del cuaternario» evidenciados por la existencia de terrazas en zonas bajas interiores relativamente elevadas, más allá de la acción de las oleadas de erosión remontante. Poco a poco, se irían conformando los paisajes naturales de nuestra zona de estudio.

Apoyándose en la existencia de un encajamiento tan destacado como es el de la confluencia de los ríos Miño y Sil en el interior de Galicia, cuyos valles 
en $\mathrm{V}$ están «coronados por un penillano más o menos claramente desenvuelto» Torre Enciso considera que el alzamiento es un fenómeno que afecta a la región gallega en general en la segunda mitad del Terciario y muy especialmente durante el Plioceno, es decir, antes de la formación de las más antiguas terrazas cuaternarias, las cuales deben su existencia a la continuación de dicho movimiento de alzamiento durante el Pleistoceno. Tras haber tratado de dar una aproximación cronológica, Torre Enciso introduce una cuestión clave de la formación de las rías al considerar como fundamentales las oscilaciones marinas glacio/eustáticas. Para él, el hecho de que los valles excavados por causa del levantamiento se prolonguen bajo el actual nivel del mar, interpretado hasta aquel momento por la tectónica, sería resultado en lo fundamental de las fuertes oscilaciones que ha experimentado el nivel marino durante el cuaternario, y que según los geólogos hay que atribuir en su mayor parte al glacioeustatismo. Se admite hoy que estas oscilaciones marinas se superpondrían a los movimientos verticales que simultáneamente podrían tener lugar tanto en el ámbito de las tierras firmes como en el fondo de los océanos». Concluye entonces que la excavación de los valles en su parte hoy invadida por el mar, se produjo durante la última o las últimas glaciaciones en las que el nivel del mar se encontraría a unos 100 metros por debajo del nivel actual y que «el mar se posesionó de la forma cóncava así creada» al producirse la transgresión post-Devensiense (post-Würm). Asigna así el mayor peso del proceso al eustatismo sin renunciar a los procesos isostáticos.

Tras esta aportación conceptual al proceso general de formación de las rías, Torre Enciso pasa a realizar el estudio de los distintos sectores litorales gallegos. Cuenta ya con una cartografía topográfica de cierta calidad. Las hojas del mapa 1:50.000 de Galicia no estuvieron concluidas hasta 1954. Las primeras ediciones de las hojas gallegas están publicadas entre 1929 (Betanzos) y 1954 (Los Nogales). Comprueba así que el alzamiento no es uniforme en el conjunto gallego, que está escindido en bloques por efecto de la orogenia alpina. Acepta como posible causa de esto el movimiento de «combadura o abovedamiento» referido por Scheu en 1913. Aprecia no sólo un alzamiento diferencial entre bloques sino también falta de uniformidad o inclinación dentro de cada uno de ellos, con claras implicaciones en la orientación de la red hidrográfica. Ello le lleva a identificar qué bloques son los que por tener fachada marítima repercuten en las rías, y así establecer diferencias en las características y evolución de cada una de estas unidades morfotectónicas. ${ }^{6}$

6. Todo esto le permite hacer la siguiente clasificación de las rías gallegas: 1. Rías del bloque septentrional o rías altas en sentido estricto, verdaderas rías transversales respecto a la costa, que adquieren su pleno desarrollo en la mitad occidental del bloque -rías de Ortigueira, El Barquero y Vivero-, mientras que en la mitad oriental, recientemente alzadas se ajustan al tipo asturiano -rías de Foz y de Ribadeo-. 2. Rías enclavadas en los bordes de la penillanura que se extiende 
La ubicación de nuestra zona de estudio nos lleva hasta las rías de Vigo, Pontevedra, Arousa,..., que ocupan las posiciones más meridionales dentro de las «Rías Bajas», con una orientación de sus ejes mayores según direcciones SO-NE. Éstas presentan una forma de embudo en planta con una anchura variable, estrechándose progresivamente hacia su vértice, y su límite hacia el Oeste, con una serie de islas, Ons y Onza en el caso de la de Pontevedra, y las Cíes, en el caso de la de Vigo (conformando las islas, junto con Salvora, el Parque Nacional de las Islas Atlánticas). La superficie que ocupa la ría de Pontevedra es de $145 \mathrm{~km} 2$, mientras que la de Vigo es de $164 \mathrm{~km} 2$. Y es que empieza, en los últimos años, a convertirse en una costumbre el que cada cierto tiempo nos sorprende en Europa, en general, España y en Galicia, en particular, una nueva catástrofe ambiental de grandes magnitudes. Catástrofe, que en el caso del Prestige, oscureció a las anteriores, entre cuyas consecuencias, con el paso de los años, ha supuesto un verdadero cambio de modelo económico de las zonas estudiadas (ver figuras n. ${ }^{\circ} 3 \mathrm{y} \mathrm{n.} .^{\circ}$ ).

En nuestra zona de estudio, los paisajes naturales han ido dando paso a paisajes claramente «antrópicos», que durante buena parte de su historia serían calificables de «rurales». En nuestra zona de estudio, algunos de ellos se conforman por Leptosoles y regosoles, suelos con espesor inferior a $30 \mathrm{~cm}$, limitados en profundidad por roca dura continua o por capas cementadas (rocas igneas postcinemáticas, en nuestro caso), «pobres», se les califica, base de la masa vegetal que observamos en la presente fotografía, consecuencia directa no sólo de los procesos de erosión recientes generados en áreas de cierta altitud, en posiciones topográficas favorables a la inestabilidad de los materiales como las zonas de cima o los rebordes de las laderas sobre los que se asientan, con fuertes pendientes. Las actuaciones antrópicas como los incendios forestales, las talas casi continuas o el pastoreo, en ocasiones excesivo, más las condiciones climáticas, como las muy abundantes precipitaciones, marcan la realidad que cincunda a la presente explotación forestal de eucaliptales (Eucalyptus globulus), que

por el noroeste gallego. Difieren profundamente de las anteriores por su orientación y desarro1lo, por lo que las distinguimos con el nombre de rías centrales. La ría de Cedeira, el conjunto lobulado del seno coruñés, y las rías de Lage, Camariñas y Corcubion pertenecen a este grupo. 3. Rías del bloque sudoccidental o rías bajas, de vastas proporciones, y que tienen de común con las del grupo anterior su condición transversal no sólo respecto a la costa, sino también respecto a la orientación de los antiguos plegamientos y unidades petrográficas. Comprende este grupo la ría de Muros y las rías pontevedresas (Vigo, Pontevedra y Arousa). En su síntesis, Torre Enciso no deja de mencionar otras cuestiones interesantes como el desproporcionado desarrollo de los valles laterales en aquellos valles transversales a las unidades petrográficas, las diferencias en altitud y anchura de las rasas septentrional y sudoccidental (ya apuntadas por Hernández Pacheco, 1950, y Lautensach, 1941) como indicadores del alzamiento desigual e inclinación, o la primordial importancia de la tectónica (del «resquebrajamiento del macizo gallego») en la génesis de las rías. 
Figura n. ${ }^{\circ}$ 3: Evolución del Modelo de Desarrollo Económico Litoral de Galicia. Rías Altas y Rías Bajas (II)

\begin{tabular}{|c|}
\hline MEDIO HUMANO \\
\hline Población y poblamiento \\
\hline $\begin{array}{c}\text { Pumento demográn algo más joven, en la costa, con tendencia a un progresivo envejecimiento, en el } \\
\text { interior }\end{array}$ \\
Emigración menor -de las comarcas del interior hacia la costa- \\
Recepción de inmigrantes \\
Galicia invertebrada \\
Red urbana más que sistema de ciudades
\end{tabular}

Fuente: Elaboración propia.

Figura n. ${ }^{\circ}$ 4: Evolución del Modelo de Desarrollo Económico Litoral de Galicia. Rías Altas y Rías Bajas (III)

\begin{tabular}{|c|}
\hline MEDIO HUMANO: EL AGROSISTEMA \\
\hline Paisajes Rurales \\
\hline Axioma: En Galicia todo es transición. \\
La diferencia entre lo rural y lo urbano obedece más a criterios de clasificación. \\
Las unidades locales casi nunca coinciden con las territoriales (aldea, barrio, lugar, casa, \\
comarca,...) (Pilar de Torres) \\
Rapidísima transformación: paso de una agricultura de subsistencia a otra de mercado Hasta \\
mediados del siglo XX: paisajes marcados por la fragmentación: \\
Dominio del monte; la agricultura se desarrollaba en los fondos de valle; \\
Paupérrimo sistema productivo (pez-vaca-árbol) \\
A comienzos del siglo XXI: el campo se ha incorporado a una economía abierta; \\
Transformación más técnica que estructural.
\end{tabular}

Fuente: Elaboración propia.

tras las distitas cortas, dejan entrever su convivencia con castaños (Castanea sativa), rebollos (Quercus pirenaica), carballos (Quercus robur),..., junto a tojales (Ulex gallii), brezales (Erica tetralix), matorrales diversos y prados de diente y seminaturales, ordenados en malla rodeados de setos vivos (de la rica flora 


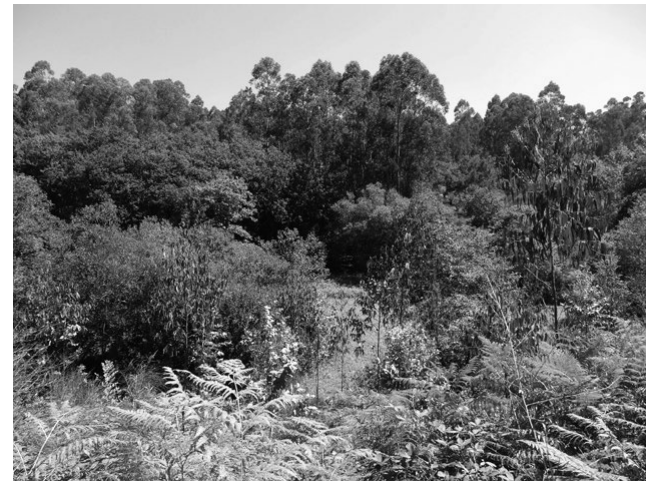

Figura n. ${ }^{\circ}$ 5: Explotación forestal, en la Península del Morrazo. Fuente: María Sotelo Pérez.

que albergan destacar la abundancia de gramineas y otras plantas) con un uso que apenas supera la economía doméstica (la sequía estival ha hecho que la respuesta humana haya sido el sustituir al ganado vacuno por el bovino o el caprino). Incluso, la gran cantidad de arroyos existentes nos muestra la aparición de pequelos bosques de galería, con abedules (Betula alba) y alisos (Alnus glutinosa) (figura $\mathrm{n}^{\circ}{ }^{5}$ ).

Buen ejemplo de paisaje en transición lo encontramos en el recogido en la presente fotografía, en la que podemos diferenciar tres partes, relacionadas con distintos tipos de explotación forestal. La primera es la compuesta por la yuxtaposición de eucaliptos, rebollos, carballo y castaños, que ocupa la mayor parte de la susodicha fotografía; la segunda, la integra la yuxtaposición de tojos, brezos, matorral,..., que se observan en un primer plano, que se dejan ver tras la corta de los eucaliptos; la tercera, en la parte central, alrededor de un supuesto curso de agua, encontramos un pequeño prado de sustitución, y un pequeño bosque galería, con abedules y alisos.

La primera parte, nos muestra el predominio de los eucaliptales que provienen del cultivo directo, y que conforman propiamente dicha una explotación forestal relacionada con el uso de su madera por parte de la industria celusosa (en concreto, en nuestro caso de la fábrica de ENCE ubicada en Marín), y, secundariamente, su uso medicinal. Como señala el Atlas de Galicia, coordinado por los profesore Precedo y Sancho Comíns, la madera de eucalipto se escinde longitudinalmente con facilidad, se deteriora pronto y no es fácil de trabajar, lo que explica que no se utilice para mobiliario o usos de calidad, y sí para la obtención de estibas, contrachapados, madera laminada, y, sobre todo, debido a sus largas fibras, para la obtención de pasta de papel; igualmente, señalar que sus hojas tienen propiedades antisépticas, por su alto contenido en cineol o eucaliptol. Además, en los último años los eucaliptos están en el centro de una notable y controvertida polémica, la existente entre los grupos ecologistas y el de no pocos científicos, pues la repercusión en el paisaje es uno de los mayores inconvenientes que genera en la actualidad. En opinión de movimientos como «Amigos da terra», el avance de la especie amenaza «a todas las formaciones boscosas autóctonas», ya que, «las especies foráneas carecen de enemigos 
naturales por lo que se acentúa su carácter invasor», aseguran, a lo que se suma el carácter "pirófito» (resistente al fuego) del árbol, lo que favorece su expansión. No opinan de la misma manera desde el CIDEU, donde consideran que el eucalipto, como cualquier otra especie forestal, tiende a luchar contra sus 'vecinas' por todos los nutrientes que permiten su supervivencia, y comparan su comportamiento con el de una densa masa de alcornoques o de hayas, donde apenas crece vegetación. De una u otra forma, en lo que coinciden científicos y ecologistas es en su «indudable» utilidad industrial y comercial, y por el hecho de que su madera es barata y útil para la construcción. Cuando por motivos diversos se talan, quedan al descubierto otras especies que un nuestra zona tienen una explotación menor, pero de gran riqueza medioambiental, los castaños (cuya existencia en Galicia alcanza los 18.000 años, si bien su introducción en estas tierras fue unida a la romanización de las mismas; en los momentos actuales, los castaños de la fotografía se ven amenazados por enfermedades como la tinta, el chancro y la plaga de los incendios forestales), los distintos tipos de robles,...

La segunda parte, la integran los tojos, brezos y matorral, consecuencia directa de la acción humana como resultado de la explotación del territorio, de tal forma que en nuestra zona de estudio puede hablarse de la existencia de una cultura del tojo; de hecho, tras el benefício de la madera, el ser humano provoca mediante el fuego el retorno periódico a etapas iniciales. El fuego fue siempre una herramienta de trabajo utilizada por los agricultores gallegos, particularmente el quemado superficial del monte para el cultivo de cereales (aprovechando el aumento efímero de la fertilidad química como consecuencia de la acumulación de cenizas y, por lo tanto, de nutrientes, procedentes de la vegetación quemada) la quema de broza, etc. Sin embargo, desde finales de los años sesenta del pasado siglo, los incendios incontrolados han ido aumentando hasta alcanzar valores no conocidos históricamente. Igualmente, destacar en nuestra zona de estudio el notabilísimo valor de los brezos en la apicultura.

La tercera parte, el centro de la fotografía, la integran pequeños prados que tradicionalmente utilizaban los habitantes de las aldeas para la cría de ganado, si bien en la actualidad, poco a poco, van dando paso, junto con los alisos y abedules, a zonas de esparcimiento y ocio de personas provenientes de los grandes núcleos urbanos próximos, como Vigo, desarrollándose sendas ecológicas,... Sin lugar a dudas, el peregrino y el turista observarán paisajes similares en su recorrido, sin ser conscientes -puesto que las guías no suelen recogerlos, de procesos como los que estamos comentando.

En definitiva, que de forma lenta, pero paulatina, este espacio rural se ha ido convirtiendo en un espacio «rururbano» más de la zona de influencia de esta gran conurbación. Si otrora el minifundio, es decir, la pequeña explotación 


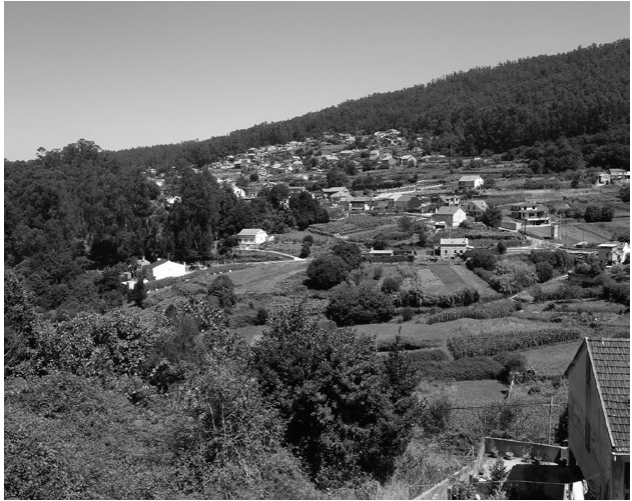

Figura n. $^{\circ}$ 6: Minifundio en espacios rururbanos. Fuente: María Sotelo Pérez.

familiar, consiguió un equilibrio entre estilo de vida, cultura y mercado, a pesar de caer en la excesiva parcelación de las fincas y predios, la estructura de la propiedad de la tierra, favoreció el logro de una dimensión suficiente para asegurar la viabilidad económica, la calidad de vida, la práctica cultural heredada y el respeto al medio geográfico natural en el que se inscribía. Sin embargo, en los momentos actuales, las pequeñas aldeas se ven transformadas por la llegada del automóvil que coadyuva a la superación de fenómenos de «enclave» o aislamiento, tal y como podemos observar en la presente fotografía, en la que los hechos morfológicos esenciales, que en otro tiempo nos mostraba el minifundio como un sistema cerrado, en la actualidad se ve superado por nuevas razones humanas y económicas que se superponen a la realidad del medio físico, cuya realidad tangible esta marcada por las distintas tonalidades de verdes (masas forestales, arbolado, cultivos,..., complementados por frondoso matorral de tojo, brezos y brecina) fruto de un clima oceánico característico de la Galicia atlántica, rico en precipitaciones, aunque con veranos más bien secos, y en el que las amplitudes térmicas se ven matizadas por la referida proximidad al mar, y la ausencia de heladas (ver figura n. ${ }^{\circ} 6$ ).

El caminante, puede detenerse a observar las tres unidades de paisaje que se distinguen en nuestra fotografía, la masa forestal fruto de la repoblación realizada con Eucalyptus globulus en alternancia con el Quercus pirenaica y el Pinus pinaster, en primer lugar; la zona central ocupada por una aldea, en segundo lugar, y, por último, el espacio ocupado por las viviendas aisladas en las que la estructura de la propiedad de la tierra es el señalado minifundio, nos hace intuir que lo que eran espacios apenas habitados, están dando paso a zonas de altas densidades de población que van ocupando estos territorio, paulatinamente, generándose una cultura que podríamos calificar en transición.

La primera unidad, los espacios forestales, cubren un tercio de nuestra fotografía, destacando el eucalipto de repoblación sobre las demás especies arbóreas. Introducida como especie ornamental, hace siglo y medio, los que podemos observar en origen proceden del cultivo, si bien su notable extensión por la Península del Morrazo, se debe a su notable reproducción espontánea, 
de una especie que podríamos denominar pionera en estas tierras, cuyos suelos (moderadamente ácidos, con más de cincuenta centímetros de profundidad, y no encharcados) son muy aptos para su reproducción. Señalar, igualmente, que aunque en origen su aprovechamiento fue ornamental, en la actualidad es maderera, y para la obtención de pasta de papel, en concreto en la empresa ubicada en las proximidades de Marín. Éstos alternan su existencia con distintos tipos de robles, el Carballo (Quercus robar), árboles de tronco derecho, corto y muy grueso con ramas gruesas y algo tortuosas; corteza grisácea o blanquecina, muy resquebrajada y de tonalidad parduzca en los ejemplares viejos y aislados, que en no pocos casos quedan ocultos bajos los propios eucaliptos, los rebollos (Quercus pirenaica), el castaño (Castanea sativa) y un denso y rico sotobosque de arbustos, hierbas y matorrales, que en no pocos casos se ha idealizado como en la maravillosa obra el «Bosque encantado», de nuestro admirado Wenceslao Fernández Florez.

La segunda unidad, la aldea, un grupo de población bastante pequeño; cuarenta a sesenta casas habitadas por otras tantas familias, dispuestas alrededor de una iglesia o de una ermita, lugares en los que se venera el Santo patrono (en nuestro caso la de Meiro), compuesta en origen por edificios pequeños y de escaso mérito artístico, a los cuales rodea una extensión que es a la vez cementerio de los aldeanos. Partiendo de la idea de que se fundaban en los lugares donde el terreno es más fructífero, es decir, en las vertientes de los montes, al respaldo de los vientos, la de la fotografía se asienta en la solana, sobre un pequeños valle, cercanas a las corrientes de los ríos y arroyos, cuyas aguas utilizaban los aldeanos para el riego, y que en los momentos actuales quieren que sus notables mansiones se surtan de las aguas «traídas» por la Mancomunidad del Morrazo (lejos queda el proceso según el cual, de los tres círculos sociales de la organización celtíbera, tribu, clan y familia, el segundo parece haber sido el progenitor de la aldea; éste, estuvo constituido por la reunión de todas las familias de colaterales que procedían de un solo ascendiente, agrupadas alrededor de su jefe; la aldea procede de un corto número de familias que han ido aumentando por las uniones sucesivas de varones y hembras y algún elemento extraño de otro grupo de población cercano que ha venido a la aldea).

La tercera unidad, está marcada por viviendas dispersas cuya disposición en el territorio no sólo se concreta en el aislamiento, sino por una estructura de propiedad de la tierra que tradicionalmente se ha denominado «minifundio». El minifundio y la explotación familiar era entendida como una pequeña propiedad agraria incapaz de asegurar el sustento básico para todos los miembros de la unidad familiar y fuente de muchos de los males que acaecían a la sociedad gallega; además el minifundio era el origen de los pleitos y litigios que, por la definición de lindes entre parcelas, eran demasiado frecuentes en el medio rural 
gallego. Hoy en día en Galicia el minifundio y la explotación agraria familiar se pueden llegar a definir como un estilo de vida que, adaptado a un mundo rural postproductivista y multifuncional, pierde sus connotaciones negativas. Como señalan autores como Ferrás, la contraurbanización contracultural impulsa un reciente poblamiento en pequeñas ciudades, villas, pueblos y aldeas y la desaparición de los flujos migratorios del campo hacia la ciudad, y esto genera una diversificación funcional, económica y cultural que puede revertir en nuevas posibilidades de desarrollo para los espacios rurales y menos desarrollados; todo ello en connivencia con unas normas que poco a poco van calando en el mundo rural de Galicia (normas subsidiarias, «Planes Xerales de Ordenación Urbana», Leyes del Suelo,...), en general, y en esta zona de expansión de Vigo, en particular.

De esta forma, en el ámbito de los paisajes antrópicos desempeñan un papel fundamental los calificables de «urbanos». De forma concreta, en el denominado Camino portugués, juegan un papel fundamental los que integran ciudades como Pontevedra, lugar de tránsito de notable interés para el peregrino o para el turista. Los más de ochenta mil habitantes de la ciudad de Pontevedra, capital de la provincia de igual denominación, han sabido conservar una ciudad cuyo origen romano -Pontus Veteris-, se ha gravado en la gran cantidad de puentes que intentan salvar en su desembocadura en la ría, las aguas del río Lérez. Sobre ellas se alza un casco antiguo declarado Conjunto Histórico Artístico en los años cincuenta del pasado siglo; se trata de un entramado vial integrado por notables plazas en las que confluyen bellísimas calles asoportaladas y peatonalizadas, que en los prolegómenos del siglo XxI está logrando un equilibrio entre la ciudad soñada y la ciudad real. Pontevedra progresivamente se está convirtiendo en una ciudad reflexiva, consciente de la importancia de la búsqueda del equilibrio entre el mercado y la capacidad de actuar en sus monumentos civiles, religiosos o en sus hermosas casas señoriales. Ayer el río y la ría marcaron su expansión y evolución urbana, hoy asistimos a una adaptación y transformación de un medio ambiente físico y antrópico en el que conviven espacios naturales y culturales, con un modelo de desarrollo síntesis de nuevos procesos de producción, y sobre todo de consumo. Lo que podemos aprender y enseñar investigando este territorio, es que nos encontramos ante una ciudad en la que convine en equilibrio la imaginación y los deseos colectivos. A partir de las «miradas» del peregrino o del turista podemos diseñar un posible «itinerario» integrado por los paisajes urbanos con los que se podrá encontrar el viajero (figura $n .^{\circ} 7$ ).

El turismo se está convirtiendo en uno de los sectores fundamentales de la economía de Pontevedra, sin embargo, no está exento de problemas, riesgos y dificultades, no sólo en materia de conservación sino también de puesta en valor $\mathrm{y}$, por ende, de gestión del propio patrimonio (ya sea a la hora de conciliar uso residencial con el turístico de la propia ciudad, la dotación de infraestructuras 


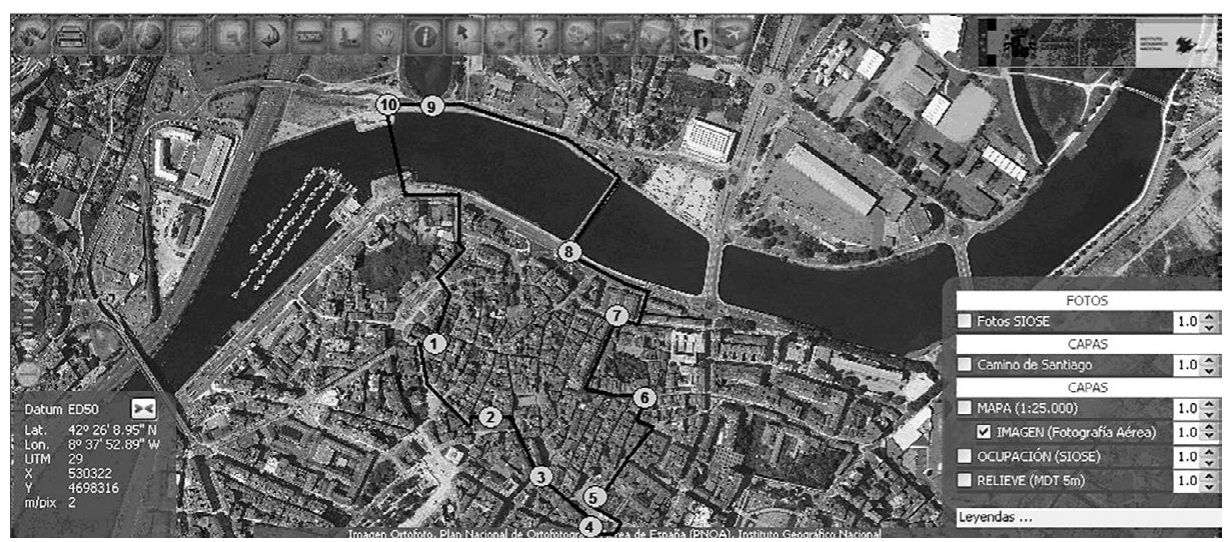

Figura n. ${ }^{\circ}$ 7. Paisajes y paisanaje de Pontevedra.

necesarias, proyectos de información y documentación no sólo para turistas sino también para residentes...). Al abordar la problemática entre turismo y el propio patrimonio, las dificultades para compatibilizar conservación y explotación adquieren características específicas. El análisis de dicha problemática que se da entre la ciudad de Pontevedra y el turismo se ha de abordar de manera global en el ámbito local del propio centro histórico de la ciudad, en la que la propia ciudad es un ente «vivo» y dinámico en el que la gestión de la explotación turística $\mathrm{y}$, por ende, conservación de un patrimonio explotado a través del turismo, se enfrenta a peligros propios como el deterioro físico.

Un posible itinerario que puede seguirse para llegar a entender los paisajes urbanos con los que se encuentra el peregrino y el turista del denominado «Camino portugués» englobaría al menos diez hitos paisajísticos; a saber:

1. Basílica de Santa María.

2. Teatro Principal y el Liceo del Casino.

3. Plaza de Curros Enríquez.

4. Santuario de la Virgen de la Peregrina.

5. Plaza de la Herrería.

6. Esquina c/Padre Sarmiento y c/Figueroa

7. Mercado de Abastos de Pontevedra

8. Vista de la ciudad desde el Puente del Burgo.

9. Espacio Natural de Xunqueira de Alba: Las marismas.

10. Vista de la ciudad desde el Puente de las Corrientes.

Detengámonos en el tratamiento de cada unos de ellos: 
1. Basílica de Santa María. (Avenida de Santa María, 24)

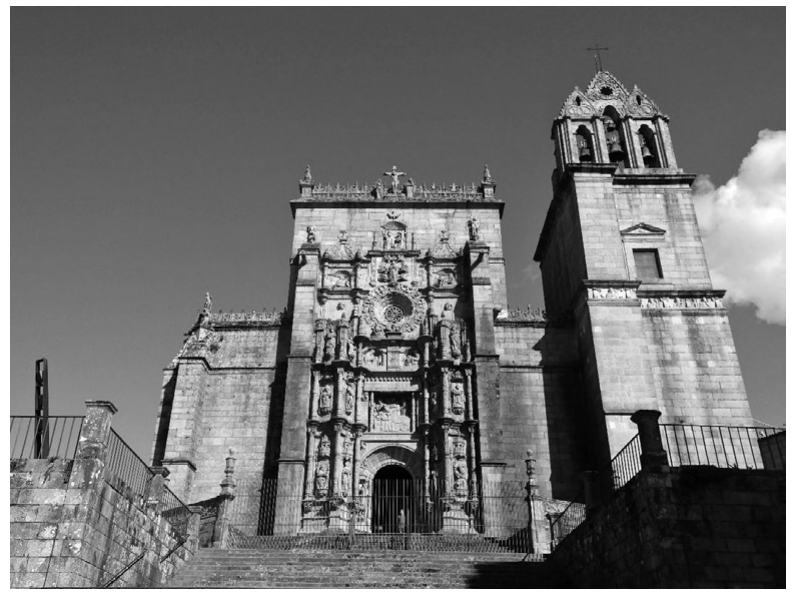

Fuente: Ignacio Sotelo Pérez

La Basílica de Santa María, conocida con el sobrenombre de Santa María de los Pescadores, pues se levantó con las aportaciones del entonces conocido como Gremio de los Mareantes, descansa sobre los restos de un edificio románico, anteriormente existente, que databa del siglo XI, con unos valores intrínsecos de notable interés. En los momentos actuales junto con su función de culto, ha tomado otras propias de un espacio de carácter cultural, cuyo uso facilita las labores del ocio y del turismo. En ella conviven diferentes estilos arquitectónicos desde el gótico al renacentista plateresco, confiriendo al entorno nuevos aires culturales a una ciudad, pequeña y recoleta, cuyo casco histórico nos muestra la adaptación de las obras de tiempos pretéritos a unas nuevas funciones urbanas, en una ciudad cosmopolita, verdadero protagonista de la planificación urbanística actual de su entorno, en un casco urbano declarado Conjunto Histórico Artístico.

\section{Teatro Principal y Liceo del Casino. (c/ Tetúan)}

Los espacios culturales presentan cambios históricos tan notables como el acaecido en el Teatro Principal y Liceo del Casino, de Pontevedra. Ayer su solar lo ocupaba la iglesia de San Bartolomé el Viejo, hoy uno de los edificios que han sabido adaptarse en el tiempo -incendio de 1980 - y en la actualidad al Plan Xeral de Ordenación Urbana -peatonalización de las calles circundantes- de Pontevedra. El edifico de estilo modernista, se ha construido en roca granítica, en consonancia con el entorno del propio casco histórico. 


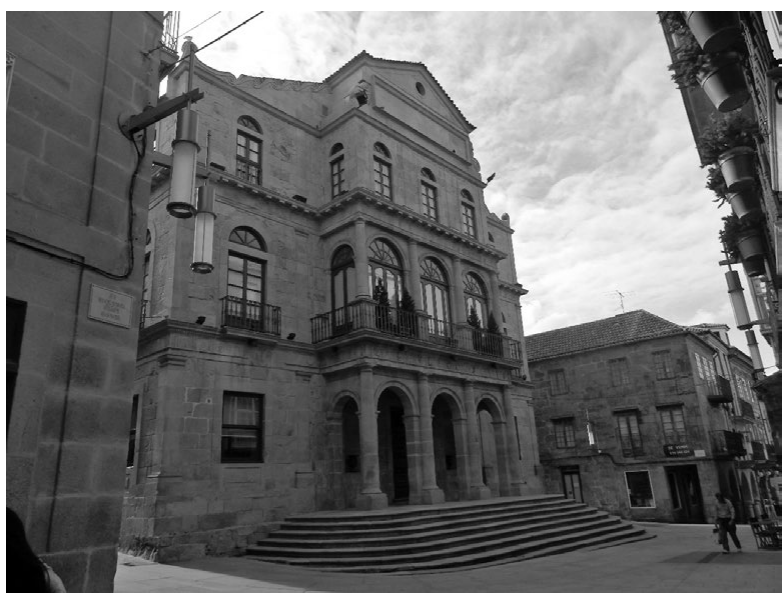

Fuente: María Sotelo Pérez

3. Plaza de Curros Enríquez (Plaza de Curros Enríquez)

La Plaza de Curros Enríquez se ha consolidado como un espacio para ser vivido y sentido. Vivido por las gentes de Pontevedra que pasean bordeando la fuente, vestigio que data de finales del siglo XIX, que ayer apagaba la sed de los pontevedreses, y hoy alegra la vista de los viandantes. El entorno conformado por edificios de épocas diversas, construidos con materiales heterogéneos -piedra, ladrillo,...-, ha sabido hacer de este entorno complejo en uso y funciones -comercial, ocio,...- una forma de vida de disfrute del medio ambiente urbano -terrazas, restaurantes, residencias,...; es decir, sentido.

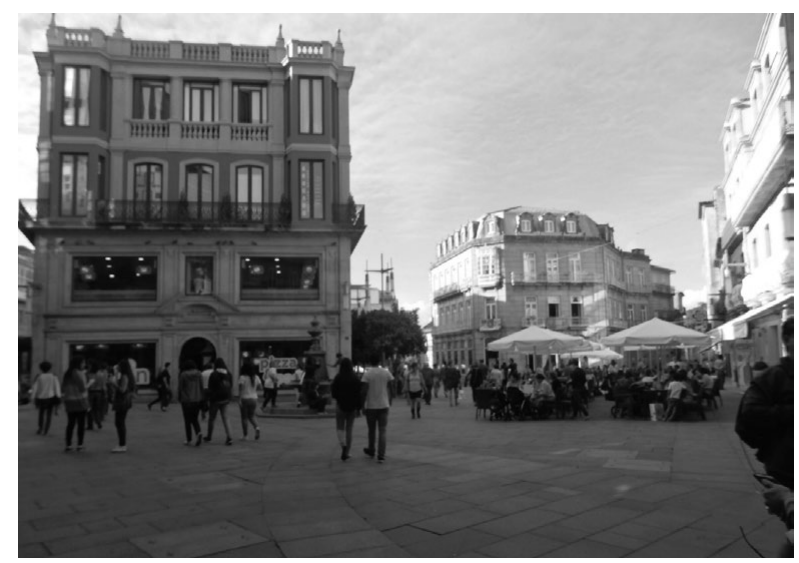

Fuente: María Sotelo Pérez 
4. Santuario de la Virgen de la Peregrina. (Plaza de La Peregrina)

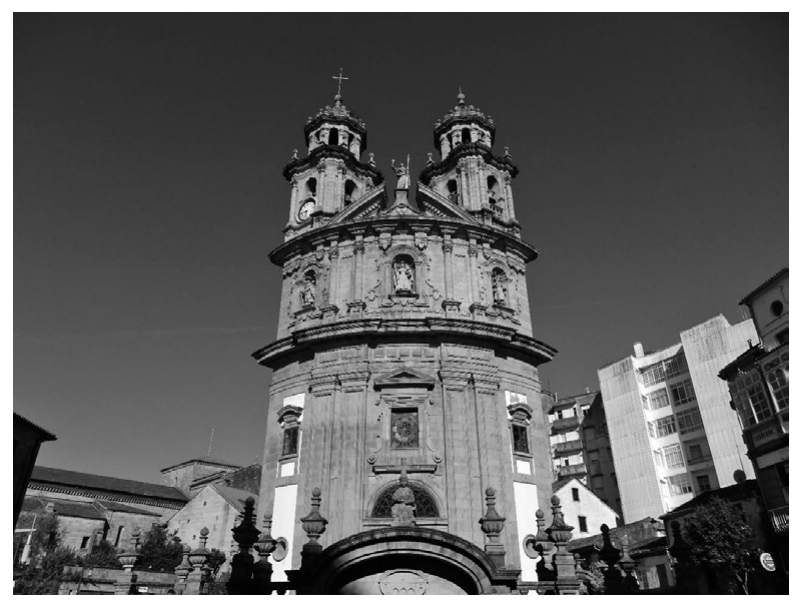

Fuente: Ignacio Sotelo Pérez

Como en no pocas ciudades españolas, Pontevedra presenta unos espacios percibidos que conforman centros o hitos urbanos. Este es el caso del Santuario de la Virgen de la Peregrina, construido a partir de 1778, al estilo de las capillas gallegas de planta central, con forma de concha de vieira, en roca granítica. En ella se conjuga con perfección el suelo y el vuelo, aunque tal y como podemos observar, su entorno urbano no siempre ha sido el adecuado, construyéndose a su alrededor, a finales de siglo pasado, edificios que hacen casi imposible pensar en las alturas, como algo metafísico.

\section{Plaza de la Herrería. (Plaza de la Herrería)}

El centro de convivencia de la ciudad se sitúa en la plaza de la Herrería, lugar en el que convergen el pasado histórico que se refleja en edificios singulares como la iglesia de San Francisco, de los siglos XIII al XVIII, y la urbanización $\mathrm{y}$ «peatonalización» de su entorno, en los prolegómenos del siglo XXI. Ayer las desamortizaciones que hicieron cambiar de dueño buena parte de sus dependencias -v.gr.: el actual edificio de Hacienda, en el ondean las enseñas de España y Galicia, hoy en venta,...-, el presente y el futuro en la confluencia de funciones comerciales, de ocio y cultura. 


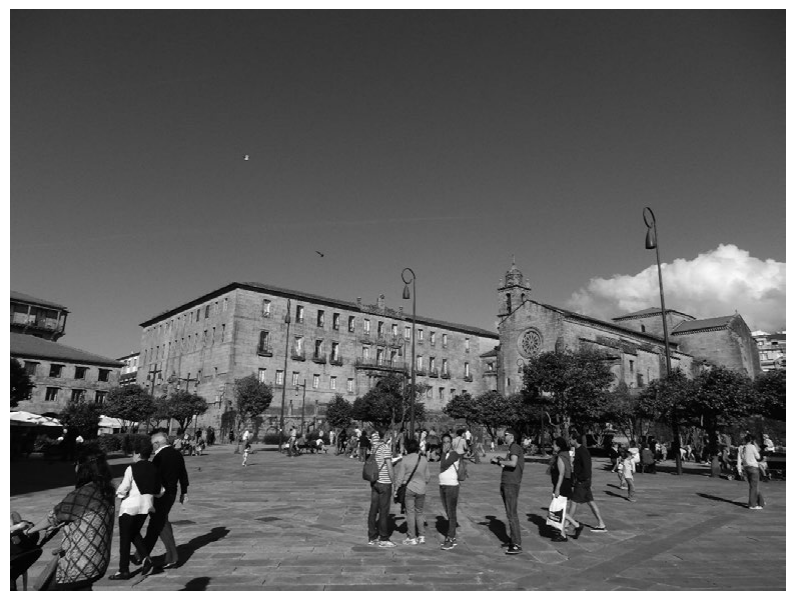

Fuente: Ignacio Sotelo Pérez

6. Esquina calle Padre Sarmiento con calle Figueroa

El trazado del denominado Casco Histórico presenta en la actualidad las consecuencias de la yuxtaposición en un espacio concreto, de funciones complejas, al albor en no pocos casos del libre juego de las fuerzas especulativas del mercado. Esto se concreta en la pervivencia de la función residencial en edificios remodelados o en remodelación, en alternancia con las comerciales y de ocio, junto con símbolos religiosos del pasado, reminiscencias de otros tiempos y cultura, como por ejemplo el crucero, en concurrencia con una compleja accesibilidad.

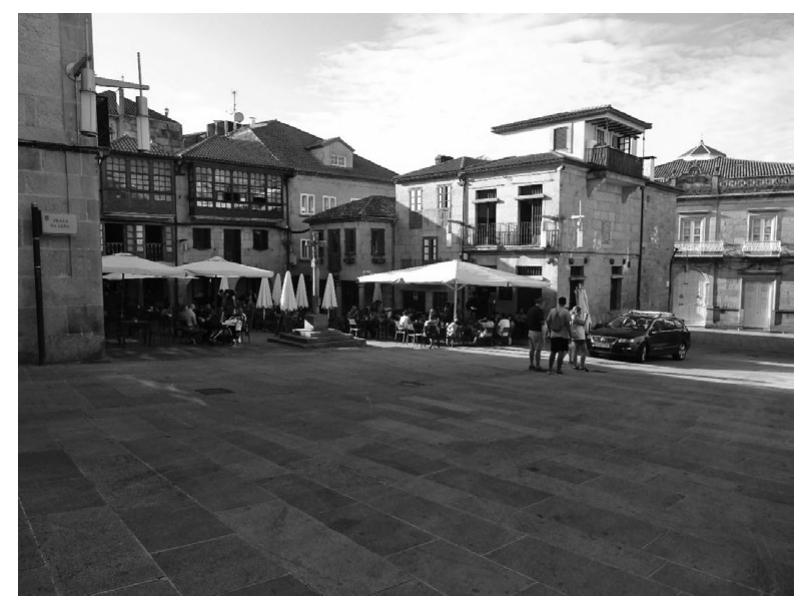

Fuente: María Sotelo Pérez 
7. Mercado de Abastos de Pontevedra. (c/ Sierra, 5)

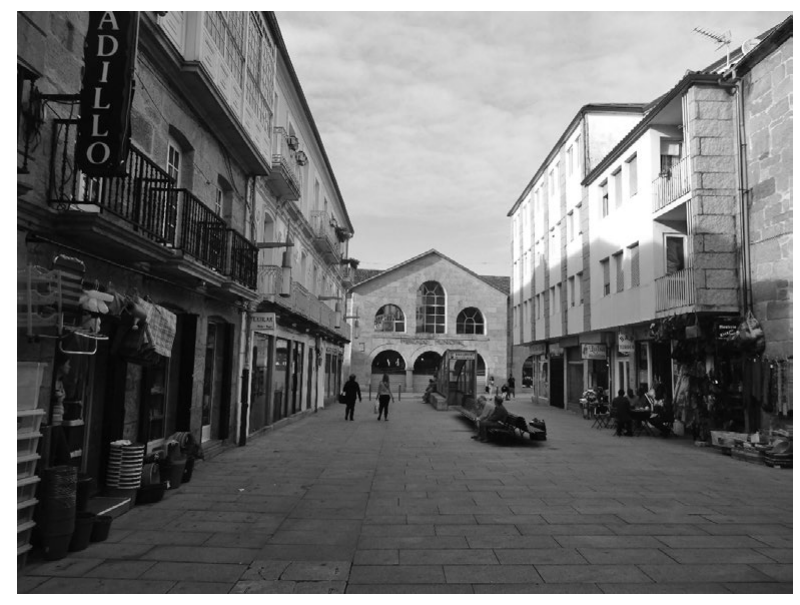

Fuente: Ignacio Sotelo Pérez

En la confluencia de las calles César Beante, y, Sierra encontramos un edifico singular que es el Mercado o plaza de abastos de la ciudad. Construido en granito con tejados yuxtapuestos a dos aguas, en teja curva, ha sufrido distintas remodelaciones, la última a comienzos del presente siglo. La «peatonalización» de su entorno se ha visto complementada por la construcción de un aparcamiento subterráneo cuya entrada observamos en la mampara cubierta. A su alrededor se genera una vida comercial complementada por la venta ambulante unida a la inmigración.

\section{Vista de la ciudad desde el Puente del Burgo. (Avenida de Uruguay, 1)}

En la desembocadura del río Lérez en la ría de Pontevedra, nos encontramos con una de las áreas de tradicionales de expansión de la ciudad. Es aquí donde se están desarrollando los últimos procesos de construcción y reproducción del espacio pontevedrés en relación con dos fenómenos complementarios; a saber: la recuperación y saneamiento del dominio hidráulico público, como es el caso del puente recién inaugurado, y los edificios en altura construidos a partir de los años ochenta del pasado siglo, en alternancia con construcciones unifamiliares, y la canalización de los desagües del margen izquierdo del río Lérez. 


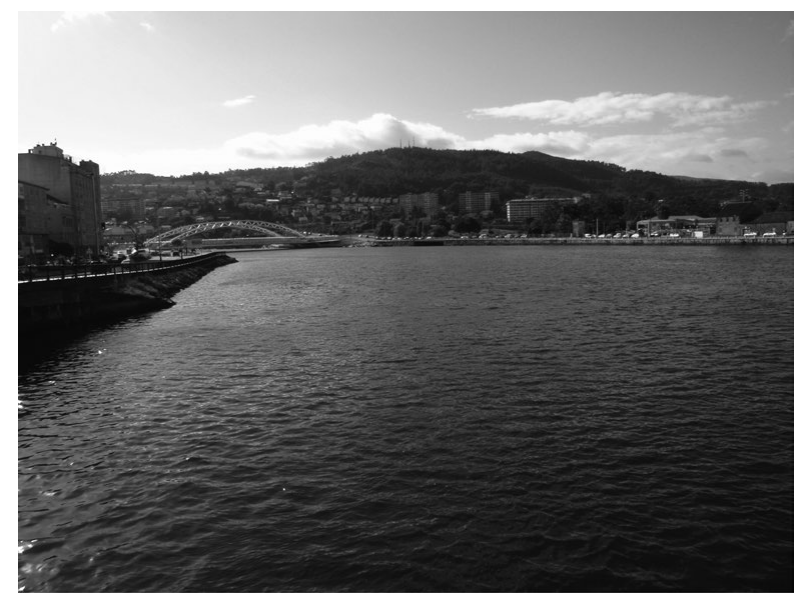

Fuente: Ignacio Sotelo Pérez

9. Espacio Natural de Xunqueira de Alba: Las marismas.(Paseo Domingo Fontán, s/n)

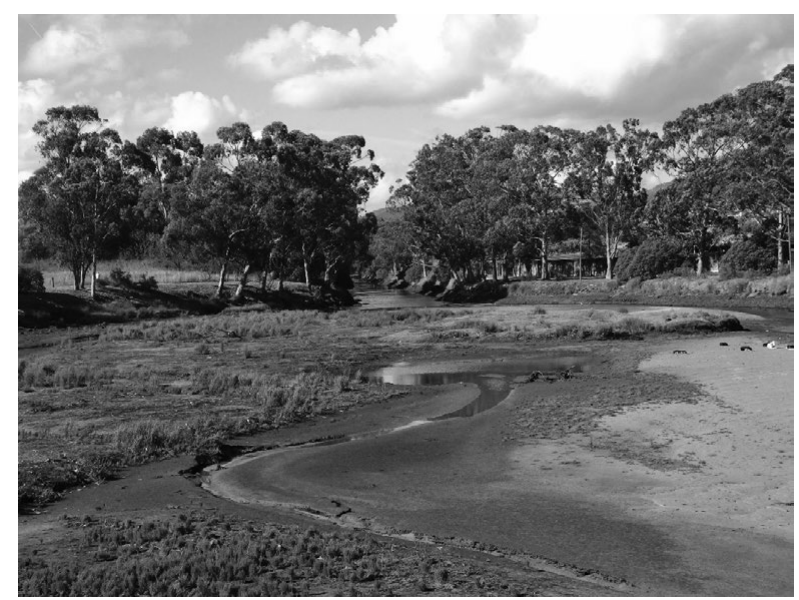

Fuente: Ignacio Sotelo Pérez

En la desembocadura del río Rons en el río Lérez, en su confluencia con la ría de Pontevedra se generan procesos de gran valor ecológico, durante los períodos intermareales. Este proceso se ha generado ininterrumpidamente desde su formación geológica hasta la ocupación del territorio por el ser humano -v.gr.: fundación de la ciudad por los romanos-. En la actualidad este espacio es conocido como la «Xunqueira de Alba», ayer marismas coto de caza y de pesca de 
la burguesía pontevedresa, hoy Parque Empresarial, en alternancia con aguas dulces y saladas en las que vive una riquísima fauna piscícola y marina. Las áreas limosas y arenosas quedan al descubierto con la marea baja, tal y como podemos comprobar en la presente imagen, en la que tras una alameda, se alternan áreas lacustres habitadas por vegetación ripícola (alnus glutinosa), juncos (juncos maritimus), «salgueiriños» (Lythrum salicaria),..., en los que vive una muy rica y variada fauna (gaviota pico amarillo, cerceta común, garzota,...).

10. Vista de la ciudad desde el Puente de las Corrientes. (Paseo Domingo Fontán, s/n)

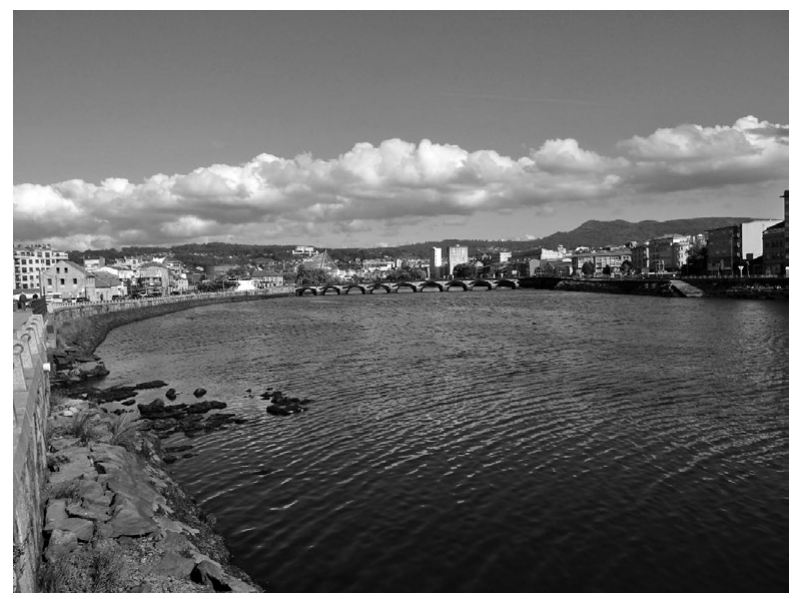

Fuente: María Sotelo Pérez

La necesidad expansiva de la otrora «Pontus Veteris», hoy Pontevedra, se ve reflejada en algunos de sus puentes, como por ejemplo el del Burgo, el de Santiago y el de los Tirantes, respuesta imprescindible desde la época de su fundación hasta la actualidad en la búsqueda de una mejor accesibilidad que no sólo salve el problema del río Lérez, sino que permita el crecimiento del casco histórico. La ausencia durante décadas de una racionalidad del crecimiento urbano se refleja en las diferentes alturas de la edificación en el margen izquierdo del río. Igualmente, debemos destacar la canalización y construcción de distintas defensas hidráulicas.

\section{A MODO DE CONCLUSIONES TOTALMENTE ABIERTAS}

Tras lo expuesto hemos podido constatar la importancia que el territorio, en general, y los espacios recogidos en los distintos paisajes que integran una 
realidad que podríamos calificar de cultural, de ello pueden colegirse las conclusiones siguientes:

Primera conclusión: En esta ruta se está dando un incremento notable, que supera el treinta por ciento lo integran, cada vez más, peregrinos -si es que se les puede seguir llamando así-, y turistas que conforman un paisanaje que, con el decurso de los siglos, se integran en los paisajes totalmente «antropizados» de un territorio con identidad geográfica propia, en la que todo es transición.

Segunda conclusión: al estudiar el paisaje, en general, y en encuadrado en nuestra zona de estudio encontramos dos grandes temas: uno es el paisaje visual, cuya consideración corresponde a un enfoque más próximo al estético; el otro es el que podría denominarse «paisaje total», que identifica al paisaje con el medio.

Tercera conclusión: En el Camino Portugués de Santiago, vuelve a ponerse de manifiesto un común sustrato, formado por un espacio, porción de terreno, situs, y una determinada percepción de ese territorio. En otras palabras, hay una realidad espacial que se percibe bajo un cierto prisma, una fuente de información más o menos directamente asimilable que se recoge también en mayor o menor medida. En este caso particular esto se manifiesta a través de una cierta virtualidad percibida por los peregrinos que, cada vez más, se han convertido en la realidad en unos nuevos turistas.

Cuarta conclusión: A lo largo de los paisajes tratados se pone de manifiesto que los sujetos de la percepción son los hombres y las mujeres que lo recorren, planteándose un interrogante totalmente abierto: ¿existe una realidad objetiva del paisaje unida a la realidad geográfica del territorio -incluso identificada con ella-, o hay tantos paisajes como percepciones o aún perceptores?

Quinta conclusión: De forma lenta, pero paulatina, los espacios rurales van convirtiéndose en un espacio rururbano, principalmente, en zonas próximas a conurbaciones como la de Vigo. Si otrora el minifundio, es decir, la pequeña explotación familiar, consiguió un equilibrio entre estilo de vida, cultura y mercado, a pesar de caer en la excesiva parcelación de las fincas y predios, la estructura de la propiedad de la tierra, favoreció el logro de una dimensión suficiente para asegurar la viabilidad económica, la calidad de vida, la práctica cultural heredada y el respeto al medio geográfico natural en el que se inscribía, en la actualidad se encuentra en rapidísima transformación.

Sexta conclusión: En el ámbito de los paisajes antrópicos desempeñan un papel fundamental los calificables de urbanos. De forma concreta, en el denominado Camino portugués, juegan un papel fundamental los que integran ciudades como Pontevedra, lugar de tránsito de notable interés para el peregrino o para el turista. Sobre ellas se alza un casco antiguo declarado Conjunto Histórico Artístico en los años cincuenta del pasado siglo; se trata de un entramado vial integrado por notables plazas en las que confluyen bellísimas calles 
asoportaladas y peatonalizadas, que en los prolegómenos del siglo XXI está logrando un equilibrio entre la ciudad soñada y la ciudad real.

\section{BiBliografíA}

AA.VV. () Atlas de Galicia. Tomo I: Medio Natural. Xunta de Galicia. ISBN: 84-453-3088-8

CASTELls, M. (1995). La ciudad informal. Alianza Editorial. http://www.pontevedraparaelmundo.es/blog/index.phpid $=186$

De la Peña Santos, Juega Puig, A., López de Guereñu Polán, J. (2012). Historia de Pontevedra. Edit Vía Láctea.

Fernández Arruti, M. ${ }^{a}$ del C. (2012). La Capilla de Nuestra Señora del Refugio La Divina Peregrina. Estudio histórico-artístico. Diputación Provincial de Pontevedra.

Filgueira Valverde, J. (1992). La Basilica de Santa María la Mayor de Pontevedra. Fundación Pedro Barrié de la Maza, Conde de FENOSA. pp. 382. ISBN: 8487819141.

ForTes, X. (2011). Pontevedra, burgo, villa, capital. Edit. Guiverny. http://ruc.udc.es/dspace/bitstream/2183/5211/1/ETSA_13-7.pdf

López Lillo, A. y Ramos A. (2010). Valoración del paisaje natural. Ministerio de Medio Ambiente, y Medio Rural y Marino. pp.212.

Pagés Valcarlos, J.L. y Vidal Romaní, J.R. (1998): Síntesis de la evolución geomorfológica de Galicia Occidental. Geogaceta, 22: 119-122.

Pagés Valcarlos, J.L. (2000). «Origen y evolución Atlánticas de Galicia». Rev.Soc. Geol.España; 13(3-4)

Torre Enciso, E. (1954): Contribución al conocimiento morfológico y tectónico de la Ría de la Coruña. Bol. R. Soco Esp. Hist. Nat. (Geol.), 50 (11): 21-51.

Torre Enciso, E. (1958): Estado actual del conocimiento de las rías gallegas. En: Libro Homaxe A Ramón Otero Pedrayo, Trab. Lab. Xeol. Laxe, 7: 237-249.

Sotelo Navalpotro, J. A. (2008). «Medio Ambiente y Desarrollo Local, algo más que dos estereotipos». Observatorio Medioambiental, vol. 11. pp. 77-105. ISSN: 11391987. ISSN-e: 1988-3277.

http://revistas.ucm.es/index.php/OBMD/article/view/OBMD0808110077A/21288

Sotelo Navalpotro, J.A. (2007). Medio Ambiente, Desarrollo y Sostenibilidad. Modelos y políticas de actuación contradictoria. Oxford University Press. pp. 428.

Sotelo Navalpotro, J.A. (2003). Desarrollo y Medio Ambiente en España: algunas consecuencias directas emanadas del hundimiento del Prestige. Anales de Geografía de la UCM, n. ${ }^{\circ} 23$.

Sotelo Navalpotro, J. A. (1991). « La degradación de la península del Morrazo». Nueva Revista de Política, Cultura y Arte, n. ${ }^{\circ} 20$. ISSN: 1130-0426.

Sotelo Navalpotro, J. A. (1995). «Reflexiones sobre el medio ambiente y la gestión de los recursos». Anales de Geografía de la Universidad Complutense de Madrid, vol. 15. pp. 681-695. ISSN: 0211-9803. ISSN-e: 1988-2378. http://revistas.ucm.es/index.php/AGUC/article/view/AGUC9595220681A/31608

Sotelo Pérez, M. (2012). Turismo y ciudades patrimoniales: Estudio de caso, Santiago de Compostela. M+A, Revista electrónica de Medio Ambiente. pp. 62-107. 